\title{
Chondrichthyans from the Grippia bonebed (Early Triassic) of Marmierfjellet, Spitsbergen
}

\author{
Janne Bratvold', Lene Liebe Delsett' \& Jørn Harald Hurum \\ ${ }^{1}$ Natural History Museum, P.O. Box 1172 Blindern, 0318 Oslo, Norway. \\ E-mail corresponding author (Jørn Harald Hurum): j.h.hurum@nhm.uio.no
}

The Grippia bonebed is located at Marmierfjellet in Flowerdalen, Isfjorden area of Spitsbergen. The bonebed occurs in the Vendomdalen Member, Vikinghøgda Formation, Early Triassic (Spathian). It is unique in Spitsbergen because of the richness of chondrichthyans, osteichthyes, amphibians and ichthyopterygians. This paper focuses on the chondrichthyans with more than 550 chondrichthyan teeth studied, together with three fin spines and one cephalic spine, assigned to 7 genera and 15 species, 8 of which are new from the Grippia niveau. The Hybodontiformes represent five of the identified genera, where most of the identified species belong to Hybodus and Acrodus. Hybodus sasseniensis, previously recorded from the older Dienarian substage, and is now shown to occur in the younger Spathian substage, and suggested to be the senior synonym of H. rapax. The possibility of Acrodus scaber and A. spitzbergensis being morphospecies, and the Acrodus genus in general, is further discussed. The occurrence of Hybodus microdus in the material is uncertain since it is shown that the mesio-distal length of the teeth is much larger than described by Stensiö in 1921. The Neoselachii (modern shark), previously only known from a fin spine of Nemacanthus from the Triassic of Spitsbergen, is now described from teeth belonging to possibly two new neoselachian species. They are referred to Synechodontiformes 1 and 2, awaiting more material to be processed.

Keywords: Spitsbergen, Early Triassic, chondrichthyans, Grippia bonebed

Received 23. November 2017 / Accepted 21. August 2018 / Published online 4. October 2018

\section{Introduction}

\section{The Permian-Triassic Mass Extinction (PTME)}

Four lineages of fish and fish-resembling vertebrates survived the PTME; Cyclostomata, Conodonta, Chondrichthyes and Osteichthyes (Scheyer et al., 2014). One of the main groups of top predators who suffered most during the PTME were the chondrichthyans according to Benton et al. (2014) and Scheyer et al. (2014). Other studies (e.g., Schaeffer, 1973; Thomson, 1977; Patterson \& Smith, 1987; Koot, 2013; Romano et al., 2016) state that the Chondrichthyes, and most fish-like creatures in general, were practically unaffected by the mass extinction since the more mobile chondrichthyans were able to survive anoxic conditions and possessed the ability to change food sources (Hallam \& Wignall, 1997).
Twitchett (2006) suggested that the chondrichthyans may have adapted to the environmental changes by reducing body size, often called the "lilliput effect".

The marine fauna shifted from a rich Chondrichthyeslife in the Carboniferous-Permian to one dominated by the Osteichthyes in the Mesozoic and Cenozoic. This appears to be a long-term process and not a direct result of mass extinction although the latter may have intensified the process (Romano et al., 2016).

The Chondrichthyes are divided in two subgroups, the Elasmobranchii (shark, skates and rays) and the Holocephali (chimaeras). Chondrichthyans have a cartilage skeleton, which is rarely preserved, whereas their teeth, consisting of enamel and dentine and regularly replaced, are commonly found as fossils (Cuny \& Risnes, 2005). For these reasons our knowledge of

Bratvold, J., Delsett, L.L. \& Hurum, J.H. 2018: Chondrichthyans from the Grippia bonebed (Early Triassic) of Marmierfjellet, Spitsbergen.

Norwegian Journal of Geology 98, 189-217. https://dx.doi.org/10.17850/njg98-2-03 
ancient sharks is much enhanced thanks to their teeth. (Straube et al., 2008; Klug, 2010; Koot, 2013).

The majority of early sharks became extinct by the end of the Permian period, such as symmoriids, petalodontiforms, stethacanthids and bransonelliformes (Fig. 1).

The Triassic period is characterized by numerous chondrichthyan families (Patterson \& Smith, 1987;
Benton, 1998). The findings, however, are discussed because of the occurrence of morphospecies (Schaeffer, 1973; Benton, 1998). This is a common occurrence with Chondrichthyes families because of their heterodont dentition (Stensiö, 1921; Storrs, 1994).

Throughout the Mesozoic Era, radiation of the chondrichthyans gave rise to many new species in groups such as hybodont sharks, holocephalans, some ctenacanths, neoselachian (modern sharks) and the
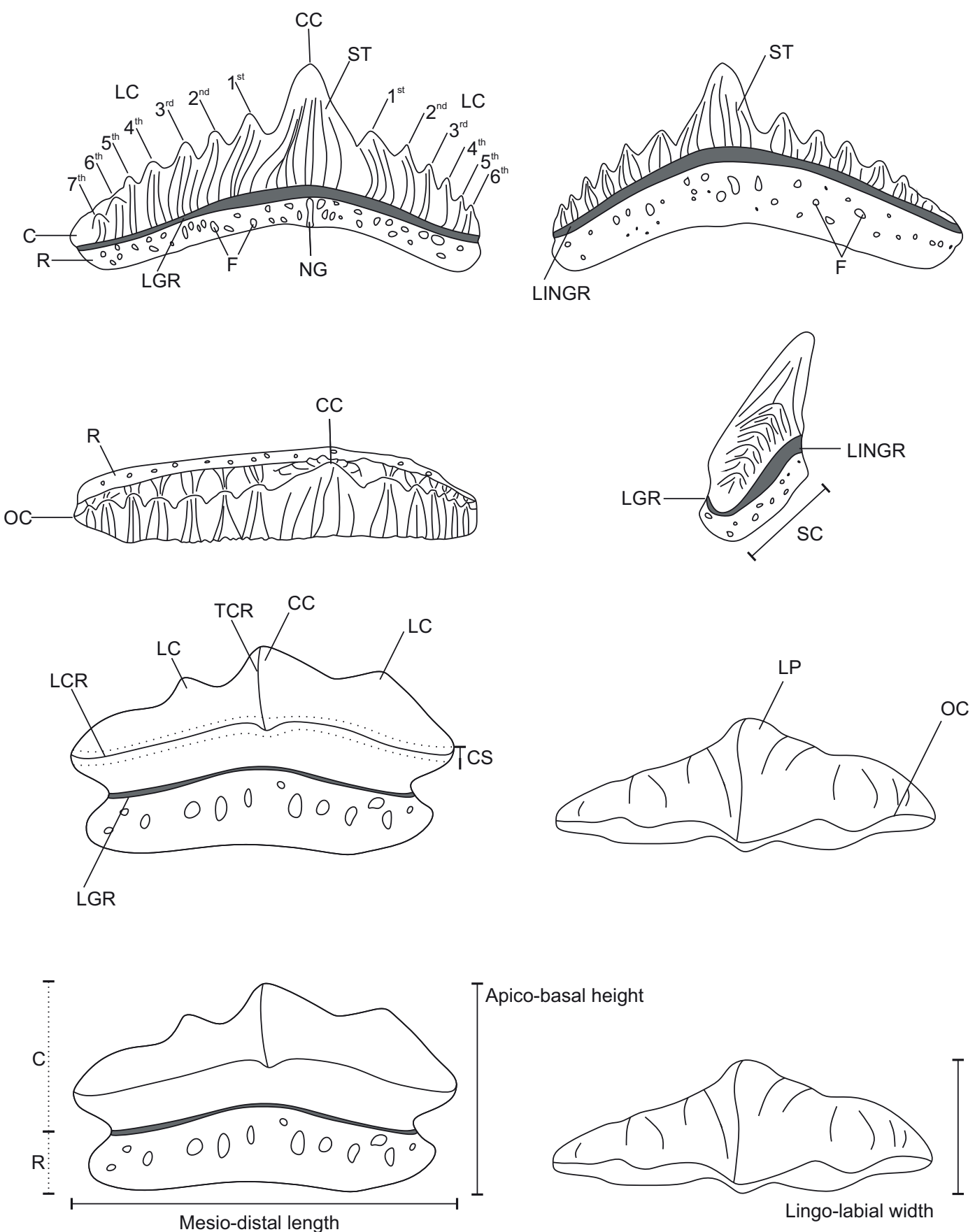

Figure 1. Abbreviations and descriptive terminology of the shark teeth described. C - crown, CC - central crown, CS - crown shoulder, LC lateral cusplet (1st, 2nd, 3rd, etc), F - foramen, LCR - longitudinal crest, LGR - labial groove, LINGR - lingual groove, LP - lingual peg, NG - nutrient groove, OC - occlusal crest, $R$ - root, SC - sulcus and ST - striations. Modified from Duffin (1985) and Koot (2013). 
batoids (e.g., skates and rays) (Long, 1995). Among the dominant groups of the Mesozoic chondrichthyans are the Hybodontiformes, which existed worldwide already in the Early Triassic (Long, 1995; Scheyer et al., 2014). They are recognized by their characteristic teeth, fin- and headspines, which are well developed in the Hybodus genus (Long, 1995; Cappetta, 2012).

Neoselachii consists of all living sharks and rays and their fossil ancestors, together with some extinct Mesozoic and Cenozoic groups (Cappetta, 1987, 2012; Klug, 2010; Guinot et al., 2012). The first great radiation of neoselachians is assumed to have been in the Rhaetian period, where a transgression leads to shallow epicontinental seas (Cuny \& Benton, 1999). Through most of the early history of the group in the Palaeozoic and Triassic, neoselachians are rare and very specialized (Kriwet et al. 2009). They developed different jaw systems whereby the jaw quickly opens and creates suction to draw in its prey. The mouth is placed underneath the head, unlike the hybodonts where the mouth was placed in front (Benton, 2015). Both the hybodonts and neoselachian have the characteristically replacement teeth, while the neoselachian additionally have a three-layered enameloid that is more resistant than the hybodonts single layered enameloid (Klug, 2010; Enault et al., 2015). The triple enameloid units enhance the preservation of neoselachians teeth (Klug, 2010). According to Klug (2008), the first large radiation of neoselachian occurred in Late Triassic-Early Jurassic, approximately 73 million years after their first known occurrence (Klug, 2008).

Eastern Greenland has the earliest record of Eugenodontiformes after the PTME in the Griesbachian (Nielsen, 1952). Here, Stensiö (1932) identified the hybodonts, Polyacrodus claveringensis and Hybodus sp. from the Induan substage. The Eugenodontiformes and hybodonts also are present from the Early Triassic (Griesbachian) at the Canadian Arctic, represented by the Caseodus and Homalodontus (Koot, 2013). From Southwestern USA (Idaho, Spathian), Evans (1904) described a neoselachian fin spine assigned to Polyacrodus sp. and hybodont teeth have been recovered (Koot, 2013). In the Early Triassic of the Boreal Sea and Eastern Panthalassa, the Eugenodontiformes, Hybodontiformes and Neoselachii occur over larger areas (Evans, 1904; Stensiö, 1932; Nielsen, 1952; Koot, 2013).

\section{Triassic chondrichthyans of Svalbard}

The PTME in central Spitsbergen is identified by Wignall et al. (1998) and Bond \& Wignall (2010) to be immediately above the base of the Vardebukta Formation. The latter provides evidence of anoxic conditions during the transition to the Triassic, as Erwin (1998) also suggested in his three phases hypothesis. This unit was studied by the early expeditions of Nordenskiöld (1864-68) in the Isfjorden area. Here, field parties discovered several horizons with fish and tetrapod remains (Nordenskiöld, 1867). Hulke (1873) erected the hybodontiform shark species Acrodus spitzbergensis from material collected by Nordenskiöld in his expedition to Saurieberget in 1864 and 1868. Stensiö (1918) gave a short report about Hybodus sp., Acrodus spitzbergensis and Gyrolepis? sp. from the Hornsund area. He compared these specimens with his own material from the Isfjorden area and found them almost identical. The material from the Isfjorden area was later described in Triassic Fishes from Spitzbergen (Stensiö, 1921). This material was collected by small expeditions, initiated by Professor Carl Wiman, in 1912, 1913, 1915-1917 and several other small expedition during 1918 (Stensiö, 1921). Stensiö (1921) established nine new shark species after his findings. The only discovery of neoselachian at Spitsbergen is a Nemacanthus fin spine, identified by Stensiö (1921) (Koot, 2013).

Cox \& Smith (1973) described two Triassic chondrichthyans collected by CASP (formerly known as Cambridge Arctic Shelf Programme) in 1969. One was a cephalic spine belonging to a hybodont shark and the other was a hybodont Acrodus tooth, which was collected at Marmierfjellet, Spitsbergen in the upper part of Vikinghøgda Formation. Birkenmajer \& Jerzmanska (1979) described material collected by the Polish Spitsbergen Expedition at Hornsund (Lower Triassic), south Spitsbergen, in 1960. The material consisted mainly of shark teeth from the genera Acrodus, Hybodus and Polyacrodus. During the Polish expedition of 1998 a considerable amount of fish remains were collected, amongst them were also shark teeth of the genera Acrodus, Hybodus and Lissodus (Blazejowski, 2004). Romano \& Brinkmann (2010) described the newly discovered shark Palaeobates polaris from the Lusitaniadalen Member, Stensiö Fjellet. From the Vendomdalen Member they recognised eight chondrichthyan taxa, where seven were identified from teeth and one from a fin spine.

The primary collection method for shark fossils from Spitsbergen has during 150 years of research probably been surface picking (Stensiö, 1918, 1921, 1932; Birkenmajer \& Jerzmanska, 1979), but this method provides only a limited amount of material and understanding.

The material for this present study is the largest sampled from Spitsbergen and was collected from the bonebed in the Grippia niveau (see Hurum et al., 2018). This unique Early Triassic bonebed gives an age constraint for the described taxa and provides a new insight for the worldwide fossil record of sharks. 


\section{Geological setting}

The Spitsbergen Mesozoic Research Group's (SMRG) expedition of 2015, concentrated on the early Triassic marine deposits in the Isfjorden area. The chondrichthyans described in this study are all from the Grippia bonebed in the Vendomdalen Member, Vikinghøgda Formation, Sassendalen Group at Marmierfjellet, Spitsbergen, for details on the geology see Hurum et al. (2018) and Hansen et al. (2018).

Wiman (1910) identified three vertebrate levels in the Sassendalen Group and labelled them the "Fish niveau", the "Lower Saurian niveau" and the "Upper Saurian niveau" based on their fossil contents. Wiman labelled a fourth layer, the Grippia niveau in 1928, which was first referred to by Stensiö (1921: XXV) as "a bonebed $33 \mathrm{~m}$ above the Fish horizon". The name is derived from the ichthyopterygian Grippia longirostris (Wiman, 1928). It also consists of ammonoids and is assumed to be an endemic fauna (Frebold, 1930). Maxwell \& Kear (2013) connected the Grippia niveau to the Vendomdalen Mb. According to Romano \& Brinkmann (2010), the Early Triassic chondrichthyan material was mainly collected from bonebeds under and above the Fish Niveau at Spitsbergen.

The Grippia bonebed excavated for this present study is located approximately $17 \mathrm{~m}$ above the Fish niveau and $25 \mathrm{~m}$ below the Lower Saurian niveau at Marmierfjellet. It is roughly $4-5 \mathrm{~cm}$ thick and consists mainly of bones, teeth and coprolites. For a stratigraphic log see Hurum et al. (2018), for detailed log and age discussion see Ekeheien et al. (2018) and Hansen et al. (2018). The material has a grey to black coloured shale matrix with yellow dolomite nodules, bones, teeth and coprolites scattered throughout. Due to the colour and moisture of the material, the different components (except the yellow nodules) are difficult to distinguish. The material is fragile, porous and breaks easily. The fragmentary fossils indicate active ocean currents that have reworked the material repeatedly, which according to Blazejowski (2004), results in a marine bonebed with disarticulated fossils.

The material analyzed is phosphatized, and X-Ray Diffraction (XRD) shows that it consists predominantly of apatite, however pyrite and dolomite/anchorite are also present. The pyrite content indicates anoxic water conditions. The presence of a tooth plate of a Ceratodus $\mathrm{sp}$. (lungfish) among the material is intriguing. The genus is today limited to brackish and freshwater (Berra, 2001), and post-Palaeozoic lungfishes are mostly found in freshwater deposits (Schultze, 2004). However, he noted that Middle Triassic occurrences of lungfish are known from marine deposits. This could indicate a possible process where sediments from coastal areas have been transported to open ocean areas. This Grippia bonebed is, in many ways, comparable to the Late Triassic Rhaetic bonebed from Devon, UK, which is a result of the Rhaetic transgression (Allard et al., 2015, Korneisel et al., 2015). The age determination of the stratigraphic log is based on ammonoids, as they provide some of the best dating from marine deposits (Hounslow et al., 2008). The biostratigraphic data are correlated with the data from the Vikinghøgda ammonoid zones in Mørk et al. (1999) and the palynology zones based on Vigran et al. (2014).

\section{Material and Methods}

\section{Material}

The material for this study was collected by The Spitsbergen Mesozoic Research Group (SMRG) during their fieldwork, August 2015 on Marmierfjellet, Spitsbergen. GPS coordinates UTM N78 30521 E16 60118, permit RiS 10227, 2015/00326-2.

Approximately 250-300 kg of material was obtained from the Grippia bonebed. From the material were 552 shark teeth, 3 fin spines and 1 cephalic spine identified. All identified specimens in this study are in the collection at the Natural History Museum, University of Oslo.

\section{Methods}

The size of the collection area was approximately 7 $\mathrm{m}^{2}$ and 5-7 cm deep. Some of the larger samples were separated and individually wrapped in aluminium foil for protection. A few of the more fragile specimens were placed in small field jackets (e.g., Hybodus rapax PMO 230.098).

The bulk material was sieved with different fractions. In this study, only the material from the $2 \mathrm{~mm}$ (largest) fraction where examined, but the other sieving samples were preserved for later micropaleontological research. Caution should be taken considering the amount of the unidentified teeth in the smaller fraction not counted.

Sieving could not remove all of the clay and minerals from the teeth so the material in this study was further treated in an ultrasonic bath, Bandelin Sonorex RK 255 Transistor, for five minutes to remove most of the adhering clay. The material consists mostly of chondrichthyan teeth. Most of these teeth were fragmented, probably a combination of preservation, permafrost, excavation, transportation, and extraction by sieving. With the aid of a binocular microscope fragments were identified, picked using tweezers, and successfully assembled and glued together using PaleoBond (type Jurassic Gel 4540) and a hardener to activate the glue (Loctite 7452). 
The remaining clay minerals on the specimens were removed by sodium bicarbonate blasting (baking soda) by Swam-Blaster (Model MV-241 Micro Abrasive Blaster) with low powder flow and air pressure. Fragile or rare, specimens (e.g., PMO 230.125) were excluded from the blasting.

Both a Nikon SLR with macro lens and a microscope (Leica MZ16 A) with Leica CLS $150 \mathrm{X}$ as lightning source and computer software (DigiCam control) were used in photographing specimens. Since the material is three dimensional preserved, the smallest specimens were photographed under the microscope by taking several pictures (10-20 pcs) with different focus, then processed in a stacking program (Helicon Focus 4.61 Lite).

Sedimentary units immediately around the bonebed were collected and samples were analysed using X-Ray powder Diffraction (XRD)-analysis to determine their composition. The XRD-data was obtained at room temperature using a Siemens D5005 diffractometer equipped with a sealed $\mathrm{Cu}$-tube housed at the Natural History Museum, Oslo. The samples were first pulverized with ethanol in an agate mortar and then the suspension was transferred to a zero-background sample holder for drying. The resulting diffract grams were analyzed with the EVA-program (Bruker) and mineral phases identified using the PDF-2 database.

Scanning Electron Microscope (SEM) analysis was performed to aid the enameloid histology of certain teeth. Only fractured specimens were used in this specific

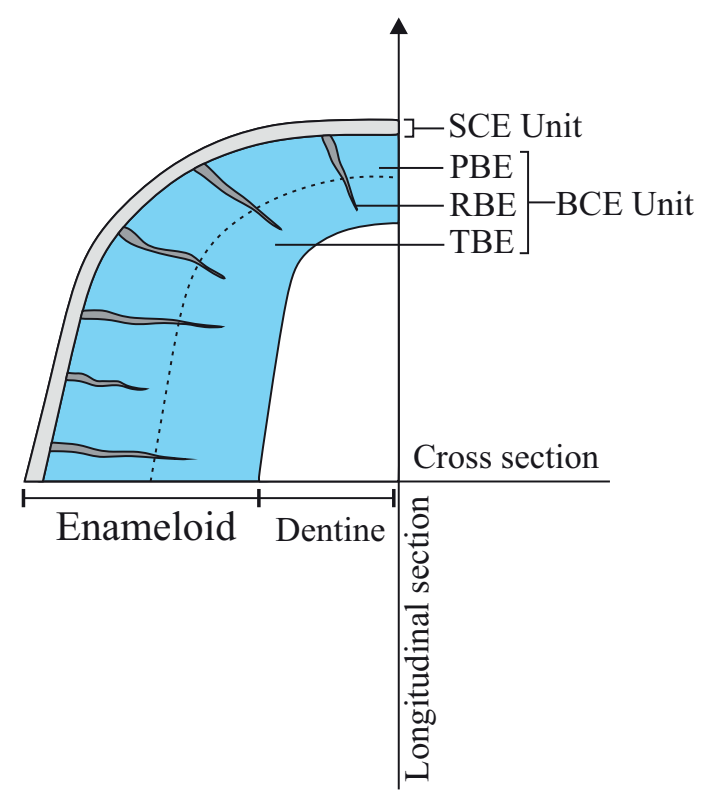

Figure 2. Enameloid histology of chondrichthyan teeth illustrating the distribution of SCE and BCE unit, with the PBE, RBE and TBE components. $B C E$ - bundled crystallite enameloid, $P B E$ - parallel bundled enameloid, RBE - radial bundled enameloid, SCE - single crystallite enameloid and TBE - tangled bundled enameloid. Modified from Enault et al. (2015). analysis. Two teeth of Hybodus rapax and one tooth of Acrodus spitzbergensis, Acrodus scaber, Polacrodus sp., Synechodontiformes sp. (1), Synechodontiformes sp. (2) were studied using the SEM. First the section was studied with a Hitachi S-3600 N Scanning Electron Microscope Energy Dispersive X-ray using an acceleration voltage between $20-25 \mathrm{kV}$. Both low and high vacuum studies were performed. The sections were polished with fine sandpaper before being etched with diluted hydrochloric acid $(\mathrm{HCl})$ at $10 \%$ for $10-120$ seconds, and then coated in a gold alloy using 'Fine Coat-Ion Sputter JFC-1100'. The gold alloy was coated 2 to 4 times for 7 min on each 90 degree angle of the analysis disk.

Due to difficulties of assigning the teeth to a right or left transverse row in the jaw, most of the direction given in the description is based on the different labial, lingual or occlusal view. The terminology of morphological features in shark teeth follows that of Duffin (1985) and Koot (2013) and a morphological key is given in Fig. 1. Fig. 2 explains the enameloid histology of chondrichthyan teeth.

\section{Institutional abbreviations:}

PMO - Palaeontological Museum Oslo (Natural History Museum, University of Oslo).

$\mathrm{P}$ and PMU - Palaeontological Institute of Uppsala

\section{Results}

\section{Systematic palaeontology}

For the measurements of the described teeth, see Table 1.

\section{Hybodus sasseniensis Stensiö, 1918} Figure 3

Material: 262 identified teeth, 258 isolated and four partly in matrix. The teeth size ranges with a mesiodistal length from $3.1 \mathrm{~mm}$ to $18.4 \mathrm{~mm}$ and a linguo-labial width of 1.2 $\mathrm{mm}$ to $7.5 \mathrm{~mm}$. Most of the teeth have broken cusps and only three of the 262 teeth have the central cusp intact. The teeth are sorted into five morphotypes, which are given in Fig. 3 as A-E. The crowns are characterized by having a large and dominant central cusp with two to seven lateral cusplets on each side. H. sasseniensis has coarse vertical striations from the labial groove (see Fig. 2 for explanation) to approximately the middle of the cusp; the rest of the apical cusp is smooth. The striations continue in general to the apex of the cusplets. PMO 230.104 (Fig. 3 B1-4) has coarser striation than PMO 230.103 (Fig. 3 A1-4), whereas the striation on PMO 
Table 1. Measurements of the described and illustrated specimens. ${ }^{*}$ - measured to the fracture point, Na- not available.

\begin{tabular}{|c|c|c|c|c|}
\hline Specimen (Tooth) & PMO Nr. & Mesiodistal (mm) & Apico-basal (mm) & Lingo-labial $(\mathrm{mm})$ \\
\hline Hybodus sasseniensis Stensiö, 1921 & 230.103 & 10.0 & $8.7^{*}$ & 3.6 \\
\hline “ & 230.104 & 9.8 & $4.8^{*}$ & $1.9^{*}$ \\
\hline “ & 230.102 & 14.5 & $5.9^{*}$ & 4.6 \\
\hline “ & 230.107 & 18.4 & $6.4^{*}$ & 3.9 \\
\hline “ & 230.101 & 12.1 & $12.0^{*}$ & 7.4 \\
\hline Hybodus rapax Stensiö, 1921 & 230.098 & 15.5 & 11.7 & 5.5 \\
\hline “ & 230.099 & $16.8^{\star}$ & $12.6^{*}$ & 6.8 \\
\hline “ & 230.100 & $8.8^{*}$ & 9 & 4.1 \\
\hline Hybodus ?microdus Stensiö, 1921 & 230.106 & 8.9 & $5.9^{*}$ & 4.3 \\
\hline Polyacrodus sp. & 230.130 & 13.3 & 6.1 & 3.7 \\
\hline “ & 230.131 & $13.1^{\star}$ & 5.1 & 2.6 \\
\hline Acrodus scaber Stensiö, 1921 & 230.112 & 31.1 & 8.2 & 5.8 \\
\hline “ & 230.113 & 18.5 & 7.7 & 5.3 \\
\hline “ & 230.114 & 18.1 & 5.6 & 4.3 \\
\hline “ & 230.133 & 21.6 & 8.8 & 6.7 \\
\hline “ & 230.132 & 22.1 & 9.6 & 7.0 \\
\hline Acrodus spitzbergensis Hulke, 1873 & 230.115 & 15.3 & 7.8 & 5.3 \\
\hline “ & 230.116 & 14.9 & 5.9 & 3.8 \\
\hline “ & 230.124 & $10.4^{*}$ & 4.0 & 3.2 \\
\hline Acrodus oppenheimeri, Stensiö, 1921 & 230.118 & 10.9 & 5.2 & 3.4 \\
\hline “ & 230.119 & 5.1 & 3.6 & 2.3 \\
\hline Acrodus lateralis Agassiz, 1839 & 230.123 & 7.5 & 3.0 & 3.5 \\
\hline “ & 230.105 & $6.7^{\star}$ & 3.0 & 2.8 \\
\hline “ & 230.144 & $\mathrm{Na}$ & $\mathrm{Na}$ & $\mathrm{Na}$ \\
\hline Acrodus gaillardoti Agassiz, 1839 & 230.120 & 10.1 & 5.4 & 5.2 \\
\hline “ & 230.108 & $7.3^{*}$ & 3.7 & 2.6 \\
\hline Acrodus sp. & 230.121 & 9.8 & 3.9 & 2.6 \\
\hline “ & 230.122 & 7.4 & 2.7 & 2.5 \\
\hline Palaeobates polaris Stensiö, 1921 & 230.134 & 7.5 & 3.7 & 2.2 \\
\hline Lissodus angulatus (Stensiö, 1921) & 230.125 & 5.1 & 2.7 & 1.9 \\
\hline Synechodontiformes sp. (1) & 230.128 & 7.2 & 5.3 & 3.2 \\
\hline “ & 230.111 & $7.9^{*}$ & 4.9 & 2.7 \\
\hline “ & 230.110 & $8.7^{\star}$ & 6.4 & 3.1 \\
\hline “ & 230.129 & 9.2 & $6.9^{*}$ & $\mathrm{Na}$ \\
\hline Synechodontiformes sp. (2) & 230.127 & 7.9 & 4.2 & 2.9 \\
\hline “ & 230.126 & $11.2^{\star}$ & 4.6 & 3.3 \\
\hline
\end{tabular}




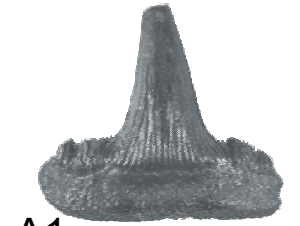

A1

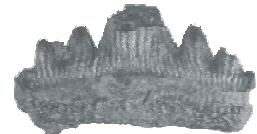

B1

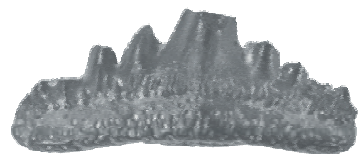

C1
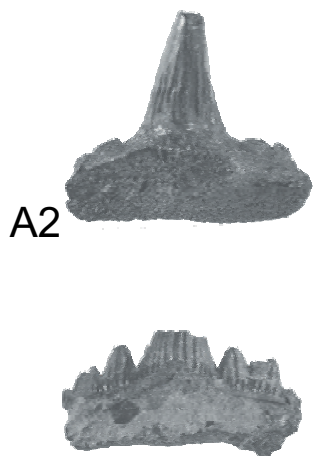

B2

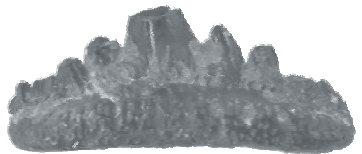

$\mathrm{C} 2$
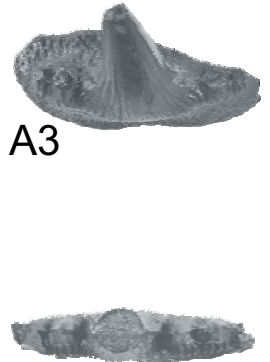

B3

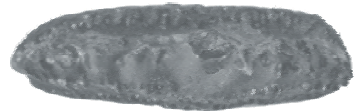

C3
A4

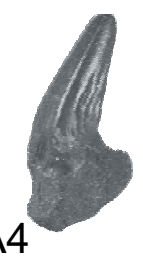

B4

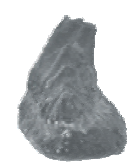

C4

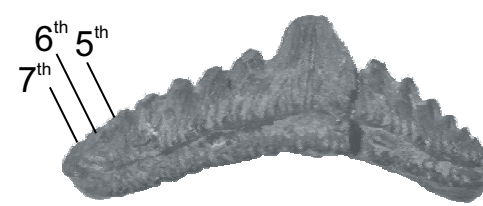

D1

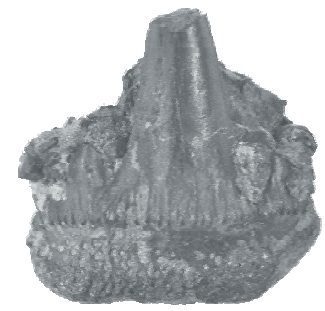

E1

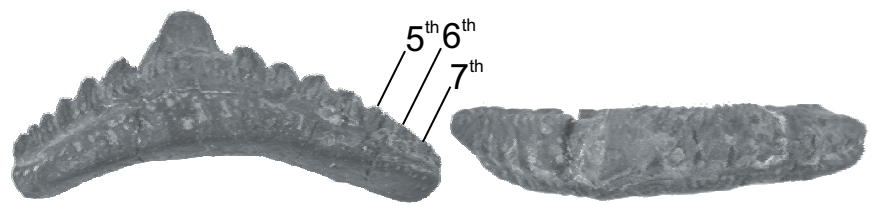

D3

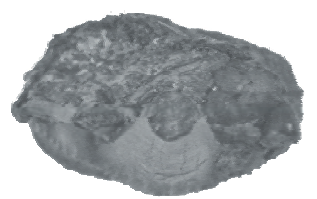

E3

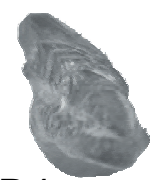

D4

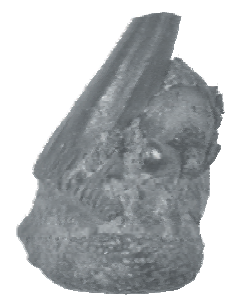

E4

Figure 3. Teeth of Hybodus sasseniensis Stensiö, 1918. (A) PMO 230.103, A1 - labial view, A2 - lingual view, A3 - occlusal view, A4 - mesio - distal view. (B) PMO 230.104, B1 - labial view, B2 - lingual view, B3 - occlusal view, B4 - mesio - distal view. (C) PMO 230.102, C1 - labial view, C2 - lingual view, C3 - occlusal view, C4 - mesio - distal view. (D) PMO 230.107 D1 - labial view, D2 - lingual view, D3 - occlusal view, D4 - mesio - distal view. (E) PMO 230.101 E1 - labial view, E2 - lingual view, E3 - occlusal view, E4 - mesio - distal view. Vendomdalen Member (Grippia bonebed), Vikinghøgda Formation, Lower Triassic (Spathian); Marmierfjellet, Spitsbergen.

230.102 (Fig. 3 C1-4) only reaches the crown shoulder in apical direction (creating furrows). The occlusal crest starts at the crown shoulder and continues almost to the apex of the central cusp, forming a slightly elevated edge on the basal parts of the central cusp. The central cusp is located in the mesiodistal centre of the tooth, with exception of PMO 230.107 (Fig. 3 D1-4) where the central cusp is offset towards the right in labial view (Fig. 3 D1) which indicates a lateral to posterior position in the jaw. PMO 230.107 has six and seven lateral cusplets, respectively to the right and left, in labial view (Fig. 3 D1). This appearance of seven lateral cusplets has so far not been described for $H$. sasseniensis at Spitsbergen. Blazejowski (2004) described teeth with one to three lateral cusplets, which were mostly located on one side of the crown. Birkenmajer \& Jerzmanska (1979) observed teeth with one to four lateral cusplets while Stensiö (1921) found teeth with up to six lateral cusplets. The tooth with six lateral cusplets (Stensiö, 1921, plate 1, fig. 10 and pers.obs. J.B.) is more similar to PMO 230.102 (Morphotype C) than PMO 230.107(Morphotype D). PMO 230.107 differs also from the others by having a clear apical concavity of both the crown and root and a seemingly lower central cusp. 
The roots are generally apico-basally narrow and in addition usually fragmented with several disorderly distributed irregular foramina and nutrient canals as seen in PMO 230.103. The base of the root is bent in apical direction that results in a slightly apico-lingually tilt of the sulcus, except for PMO 230.102 where the root base is straight.

PMO 230.101 (Fig. 3 E1-4) represents one tooth of a group of 18 more massive teeth than the remaining 244 "regular" teeth. There is no gradual size distribution between the "regular" and massive group of teeth, which is unusual. They differ from other "regular" teeth (e.g., Stensiö, 1921; Birkenmajer \& Jerzmanska, 1979; Blazejowski, 2004) by having broader linguo-labial width, but have approximately the same mesiodistal length. They range in mesiodistal length of $12.4 \mathrm{~mm}$ to $15 \mathrm{~mm}$ and linguo-labial width of $3.8 \mathrm{~mm}$ to $7.5 \mathrm{~mm}$, with a much linguo-labially broader root than all of the former described teeth (PMO 230.102-4 and 230.107).

\section{Hybodus rapax Stensiö, 1921} Figure 4

Material: 15 isolated teeth. Of the identified teeth, only two have preserved the complete mesiodistal length, at $15.5 \mathrm{~mm}$ (PMO 230.098) and $18.1 \mathrm{~mm}$. Three teeth have the apico-basal height preserved and they range from 6.7 to $11.7 \mathrm{~mm}$ while the linguo-labial width to most of the teeth ranges from 3.2 to $6.8 \mathrm{~mm}$. This species has robust teeth with one dominant central cusp.

Description: The central cusp to PMO 230.099 (Fig. 4 $\mathrm{B} 1-4)$ is pointing in the opposite mesiodistal direction than PMO 230.098 (Fig. 4 A1-4) and without any lateral cusplets the position in the jaw is anterior, but caution on designating right or left jaw should be taken as it is not possible to decide if it is from upper or lower jaw. The central cusp in PMO 230.098 is bent in both lingual and mesiodistal direction, which indicates a lateral to anterior position. The position of PMO 230.100 (Fig. 4 C1-4) in the jaw indicates to be symphyseal or anterior, based on the more lingually bent central cusp than in PMO 230.098-99. The identified teeth are significantly smaller than the teeth described by Stensiö (1921: plate 1 fig. 1 \& 2, P.41a-b and pers.obs. J.B.).

PMO 230.099 is similar to the $H$. longiconus described by Diedrich (2009, fig. 6.2) and Böttcher (2015, fig. 8.13a \& b), but without the small mesiodistal bulging of the basal part of central cusp, only labial bulging of basal central cusp. PMO 230.100 has a distinct occlusal crest, in contrast to PMO 230.098 and PMO 230.099, from the mesiodistal end apically to the apex of the central cusp.

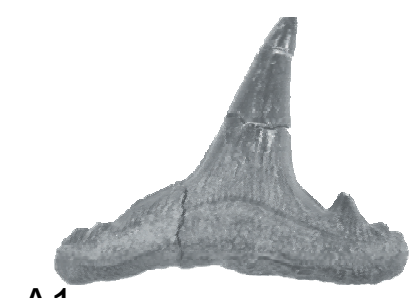

A1

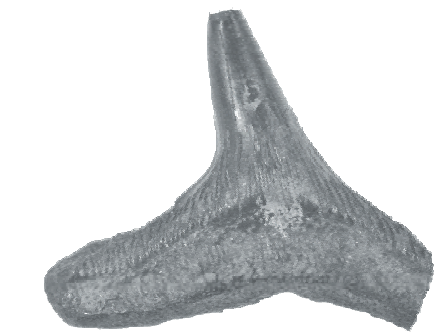

B1

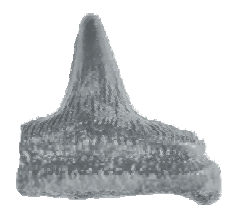

C1

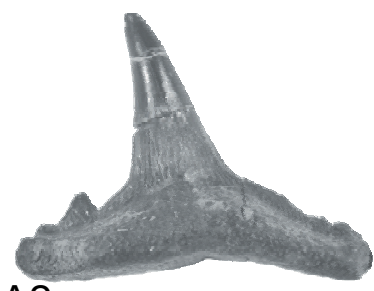

A2

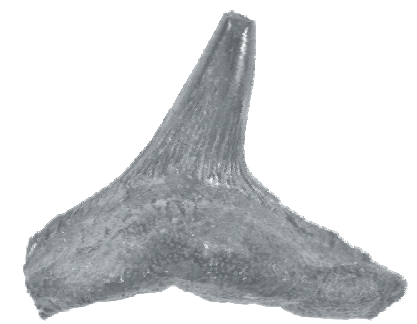

B2

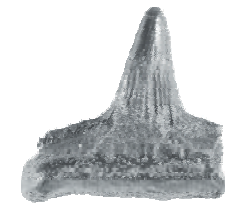

C2

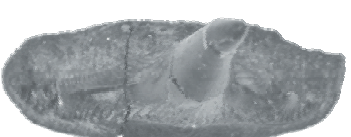

A3

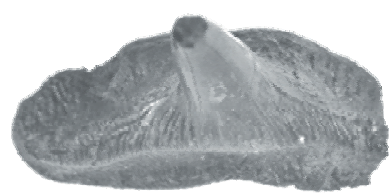

B3
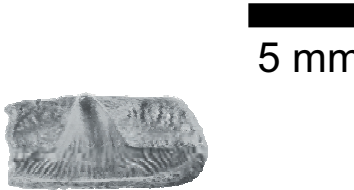

C3
A4

B4
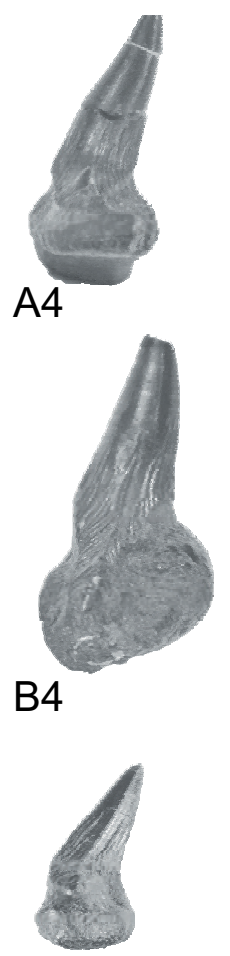

C4

Figure 4. Teeth of Hybodus rapax Stensiö, 1921. (A) PMO 230.098 left anterior-lateral tooth, A1 - labial view, A2 - lingual view, A3 - occlusal view, A4 - distal view. (B) PMO 230.099 right anterior tooth, B1 - labial view, B2 - lingual view, B3 - occlusal view, B4 - mesial view. (C) PMO 230.100 symphyseal-anterior tooth, C1 - labial view, C2 - lingual view, C3 - occlusal view, C4 - mesio- distal view. Vendomdalen Member (Grippia bonebed), Vikinghøgda Formation, Lower Triassic (Spathian); Marmierfjellet, Spitsbergen. 


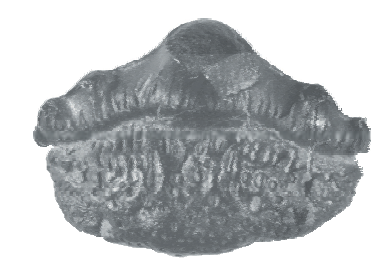

A1

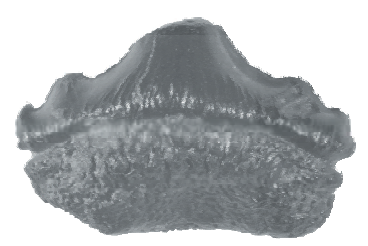

A2

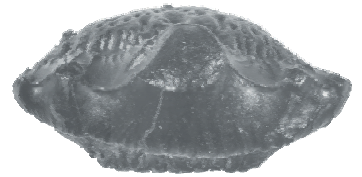

A3

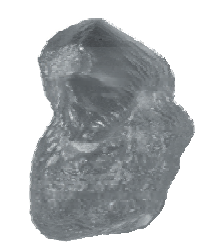

A4

Figure 5. Tooth of Hybodus ?microdus Stensiö, 1921. PMO 230.130, A1 - labial view, A2 - lingual view, A3 - occlusal view, A4 - mesio distal view. Vendomdalen Member (Grippia bonebed), Vikinghøgda Formation, Lower Triassic (Spathian); Marmierfjellet, Spitsbergen.

The vertical striations are coarse and issues from the linguo-labial groove in apical direction to the occlusal crest. By the central cusp, the striations continue apically to the cusp base. The labial striations do not encounter the occlusal crest. Rest of the crown is smooth with a shiny surface. PMO 230.098 has four lateral cusplets (Fig. $4 \mathrm{A1}$ ) oriented at the mesiodistal ends and are paired on each side, the first distal lateral cusplet is intact with an extended cusp similar to the central cusp, but blunter, and the second is smaller and more rounded. The thick linguo-labial broadness of the root is well defined (Fig. 4 A, B, C-3) and the crown is positioned in the labial root area. The central part of the root is apico-basally highest right beneath the central cusp and the labial root is apically inclined. The apical root has a distinct edge that extends almost from the mesial to the distal end and apically the root ends in a concave orientation parallel to the labial groove. The labial groove is apico-basally high and concave, which gives a short interval between the root and crown (Fig. 4A). The lingual groove to PMO 230.100 is nearly horizontal due to the root plateau extended as a line from the mesial to the distal end (Fig. 4 C1). The foramina are distributed irregular in the root and a labial nutrient groove is positioned beneath the centreline of the inclined cusp, as in Stensiö teeth (1921: plate 1 fig. $1 \& 2$ and pers.obs. J.B.), but in PMO 230.099 the nutrient groove is less prominent. PMO 230.099 is a larger and more massive tooth than both PMO 230.098 and PMO 230.100 (Table 1 ). With this new material the differences between the teeth of $H$. sasseniensis and $H$. rapax becomes unclear (see discussion).

\section{Hybodus ?microdus Stensiö, 1921 Figure 5}

Material: Five isolated teeth identified. The teeth have a central cusp and several lateral cusplets. They range from a mesiodistal length of 8.9 to $11.3 \mathrm{~mm}$ and linguo-labial width of 3.2 to $4.3 \mathrm{~mm}$. None of the apico-basal heights is intact. The teeth are much larger than for the H. microdus described before in e.g., Stensiö (1921), Birkenmajer \& Jerzmanska (1979).
Description: PMO 230.106 (Fig. 5 A1-4) has a central cusp with two lateral cusplets on each mesiodistal side (A1). The occlusal crest continues from the mesiodistal end to the fracture surfaces of the cusp and cusplets, before it initiates on the opposite side of the fracture surface. On the linguo-labial crown shoulder there are oriented vertical striations creating small furrows. The linguo-labial grooves are apical-concave, the same as the apical root (Fig. 5 A1-2). Both linguo-labial roots have the same apico-basal height, similar to Acrodus. The labial root is filled with irregular foramina disorderly distributed (A1) while the lingual root has smaller and more rounded foramina (A2).

\section{Polyacrodus sp. Jaekel, 1889 Figure 6}

Material: Three identified teeth. Only one tooth has the mesiodistal length preserved, at $13.3 \mathrm{~mm}$ (PMO 230.130), while the apico-basal height range between 4.6 to $6.1 \mathrm{~mm}$ and the linguo-labial width range between 2.5 to $3.7 \mathrm{~mm}$. $P$. sp. has a linguo-labial broad, relatively high and blunt central cusp with a lingual peg located at the basal cusp. The teeth have apical high and massive roots, as Acrodus, and a crown with brittle-shape cusplets, more like the genus Hybodus. The lateral cusplets vary from three to four on each side of the central cusp.

Description: PMO 230.130 (Fig. 6 A1-4) central cusp is located slightly to the left in mesiodistal direction (A1, labial view) of the tooth centre. The central cusp is more dominant in both apico-basal height and linguolabial broadness than PMO 230.131 (Fig. 6 B1-4), but has a blunter apex (Fig. 6 A1). The vertical striations encounter the apex of central cusp and lateral cusplets. PMO 230.130 has three poorly developed lateral cusplets, whereas there are three well-developed cusplets on each side of the central cusp in PMO 230.131 with the characteristic brittle-shape (Fig. 6 B1). The lateral cusplets are positioned closer together than in Hybodus, with a smoother transition (Fig. 6 B1) between them. The cusplets have several coarse vertical striations that reduce in number the further away from the central cusp they 


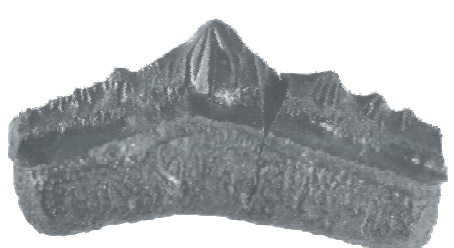

A1

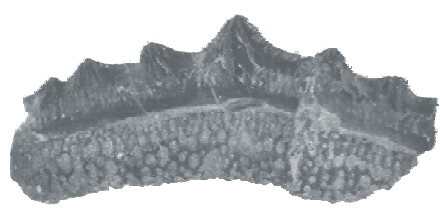

B1

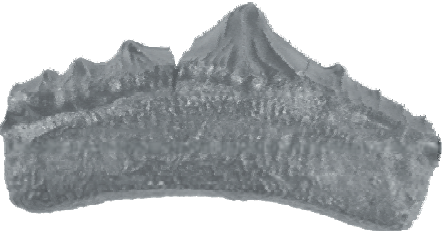

A2

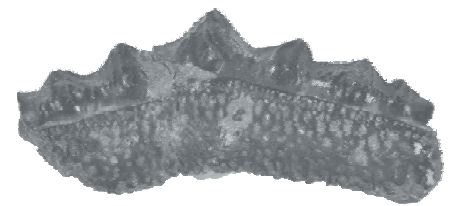

B2

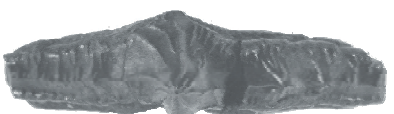

A3

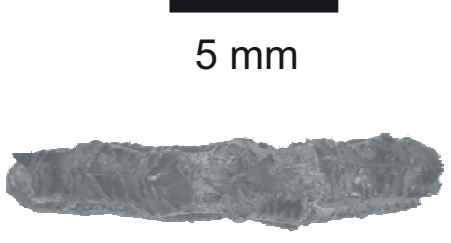

B3
A4
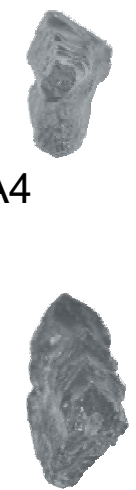

B4

Figure 6. Teeth of Polyacrodus sp. Jaekel, 1889. (A) PMO 230.130, A1 - labial view, A2 - lingual view, A3 - occlusal view, A4 - mesio - distal view. (B) PMO 230.131, B1 - labial view, B2 - lingual view, B3 - occlusal view, B4 - mesio - distal view. Vendomdalen Member (Grippia bonebed), Vikinghøgda Formation, Lower Triassic (Spathian); Marmierfjellet, Spitsbergen.

are located. Next to the two outermost cusplets in PMO 230.130, a slight elevated area indicates a fourth cusplet on each side. Based on that observation this tooth has indications of four lateral cusplets on each side of the central cusp. Polyacrodus pyramidalis (Stensiö, 1921, plate 1 , fig. 21-26) has the same lingual peg with approximately the same linguo-labial thickness compared to their mesiodistal length, but the crown has no lateral cusplets. The teeth described by Stensiö (1921) are significantly smaller (linguo-labial length of $1.5-2.0 \mathrm{~mm}$ and apicobasal height of $0.5-0.75 \mathrm{~mm}$ ) compared to the teeth described here. While the Polyacrodus polycyphus Agassiz, 1837 described by Diedrich (2009) have similar size and contains lateral cusplets.

Towards the posterior position in the jaw the number of lateral cusplets increase, roots are flatter and become more linguo-labially wide (Diedrich, 2009). PMO 230.130 has an extra pair of lateral cusplets and is linguo-labially broader, which may indicate a more posterior position than PMO 230.131. The occlusal crest is continous from the mesial to the distal direction with skewness from the center of the tooth crown towards the labial side, and is intact through the crown. This results in a crown that is broader lingually than labially. The crown shoulders have ornamentation, formed as a mesh pattern, and located on the edge before the crown angles inwards into the linguo-labial grooves. Linguo-labial grooves are deep. The root are apico-basally high, massive, but narrower than the crown, and with a slight concavity as in the linguo-labial groove and basal crown. The lingual root is apico-basally higher than the labial and both have small irregular foramina located disorderly.

\section{Acrodus scaber Stensiö, 1921 Figure 7}

Material: 41 isolated teeth well preserved and many of them complete. The teeth identified are flat, elongated and ranging from a maximal mesiodistal length of 11.2 to $31.1 \mathrm{~mm}$, apico-basal height of 4.8 to $9.7 \mathrm{~mm}$ and linguo-labial width of $3.6 \mathrm{~mm}$ to $8.2 \mathrm{~mm}$. The root is significantly apico-basal higher than the crown in most of the identified specimens, similar to Stensiös (1921) observations of $A$. scaber. A characteristic feature for this species compared to A. spitzbergensis is the radiating striations from the central part of tooth in mesiodistal and apico-basal direction to the linguo-labial grooves, in a fan-like shape.

Description: The mesiodistal longest tooth $(31.1 \mathrm{~mm})$ preserved in this material is PMO 230.112 (Fig. 7 A1-4). The tooth is rather apico-basally flat, mesiodistally elongated and fluctuates apico-basally. The apically highest part of the crown is subrounded and slightly mesiodistally bent in the vertical plane, opposite to that of $A$. spitzbergensis, which has a more angular central crown. PMO 230.133 (Fig. 7 D1-4) has a small rounded elevation in the crown centre that indicates the middle part of the tooth. The crown differs from PMO 230.112, PMO 230.113 (Fig. 7 B1-4) and PMO 230.114 by being more massive, with rounded appearance and having linguo-labial fluctuations (Fig. 7 D3). PMO 230.114 (Fig. 7 C1-4) has a significant mesial offset crown peak to the left in labial view, which indicates a lateral to posterior position in a jaw. The distal end of the tooth is lingual bent, which results in a slight labial concavity of the tooth (Fig. 7 C3). PMO 230.114 has a more distinguished occlusal crest than PMO 230.112-3 and PMO 230.13233. The striations in A. scaber radiate apically from the linguo-labial grooves to the centre top crown with creations of deep furrows on the crown shoulder. The 


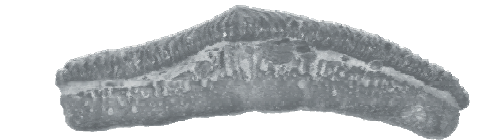

A1

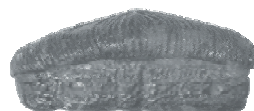

B1

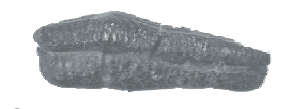

C1

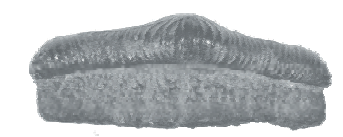

D1

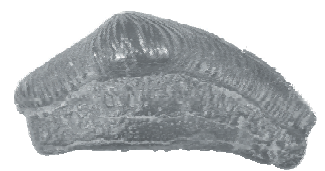

E1

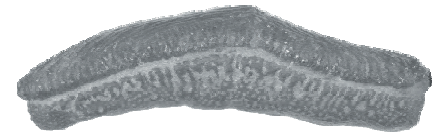

A2

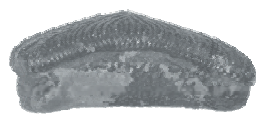

B2

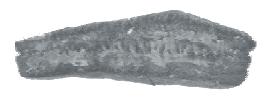

C2
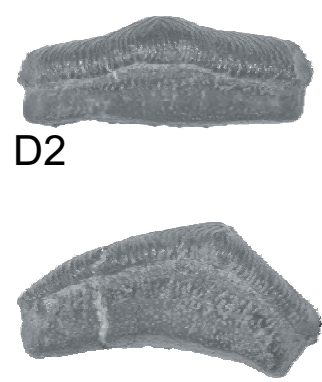

E2

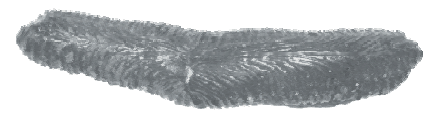

A3

A4

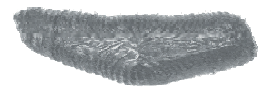

B3
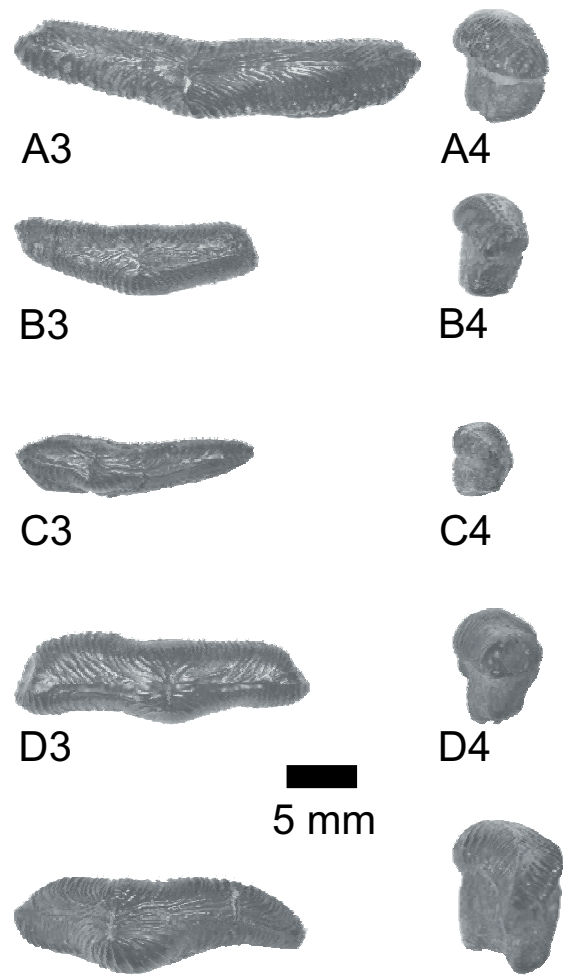

E3
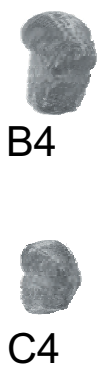

B4

C4
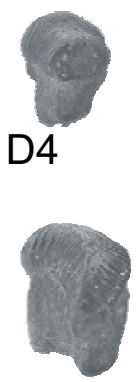

E4

Figure 7. Teeth of Acrodus scaber Stensiö, 1921. (A) PMO 230.112, A1 - labial view, A2 - lingual view, A3 - occlusal view, A4 - mesio - distal view. (B) PMO 230.113, B1 - labial view, B2 - lingual view, B3 - occlusal view, B4 - mesio - distal view. (C) PMO 230.114, C1 - labial view, C2 - lingual view, C3 - occlusal view, C4 - distal view. (D) PMO 230.133, D1 - labial view, D2 - lingual view, D3 - occlusal view, D4 - mesio distal view. (E) PMO 230.132, E1 - labial view, E2 - lingual view, E3 - occlusal view, E4 - mesio - distal view. Vendomdalen Member (Grippia bonebed), Vikinghøgda Formation, Lower Triassic (Spathian); Marmierfjellet, Spitsbergen.

linguo-labial crown shoulders are bulging over the root, however, the labial more so than the lingual, creating deep linguo-labial grooves. The root has irregular distributed foramina, where PMO 230.112 stands out by having larger foramina than PMO 230.113-4 and PMO 230.132-33. PMO 230.114 has a vertical deep nutrient groove in the labial root, beneath the apical highest part of the crown.

\section{Acrodus spitzbergensis Hulke, 1873 Figure 8}

Material: 138 isolated teeth, 19 of them complete. The teeth are ranging from 8.7 to $16.4 \mathrm{~mm}$ in mesiodistal length, 2.2 to $7.8 \mathrm{~mm}$ in apico-basal height and 1.5 to 5.3 $\mathrm{mm}$ in linguo-labial width. The highest part of the teeth is elevated to an angular cone with distinct striations radiating from the occlusal crest and central apical part basally to the linguo-labial grooves.

Description: PMO 230.115 (Fig. 8 A1-4) is labially concave with the highest cone gently mesio-distal offset towards the left (Fig. 8 A1 \& A3). Due to the almost central position of the cone, the tooth may belong to the anterior transverse rows of the jaw. This is in contrast to the skewness of PMO 230.116 (Fig. 8 B1-4), where in labial view (B2) the cone is offset towards the right in mesio-distal direction, which indicates an affinity to lateral or posterior transverse rows. The striation radiates basally from the occlusal and transverse crest to the linguo-labial grooves in short mesiodistal intervals. They are slightly elevated from the crown surface and coarser than the striations in A. scaber. Perpendicular to the main labial transverse crest are several small striations on the top of the crown, which fades out rapidly. The striations occur also lingually, but here they also radiate basally to the labial groove. PMO 230.116 has the same arrangement of the occlusal and transverse crests that radiates from the central cone in a cross-shape as PMO 230.115, but there are more striations on the central cone oriented mesiodistally closer. PMO 230.124 (Fig. $8 \mathrm{C} 1-4$ ) is a flat, elongated tooth and differs from PMO 230.115 and PMO 230.116 in not having a distinct higher part of tooth, and is the only counted specimen of A. spitzbergensis in this collection that does not have a distinct central part. The tooth is similar to Stensiö (1921: plate 2, figure 11a-c and pers.obs. J.B.), but is flatter on the apical top. The crown has coarse striations apically radiating from the linguo-labial grooves, over the crown shoulder before they narrow and terminate by the linguo-labial crown centre. Both the crown and apical 
A1

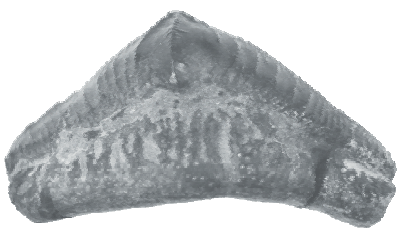

A2

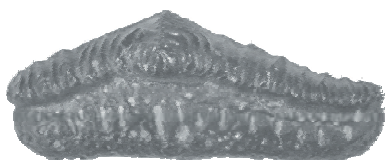

B1

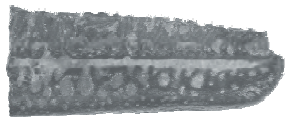

C1

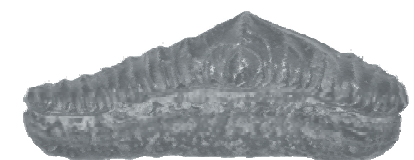

B2

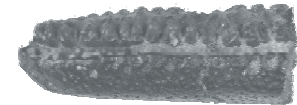

C2
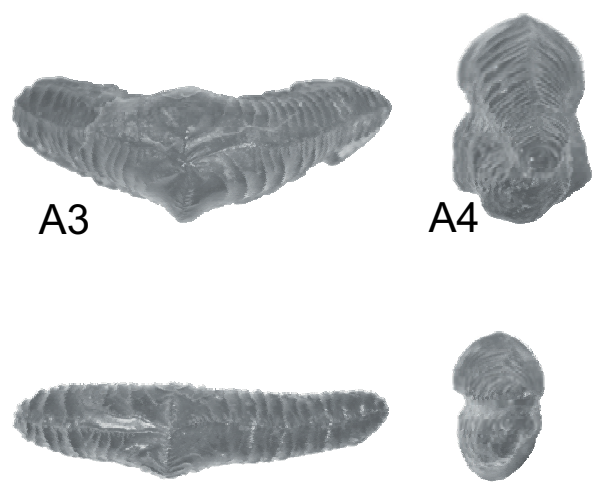

B3

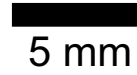

B4
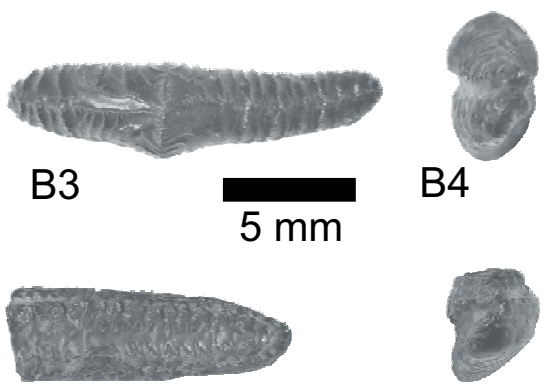

C3

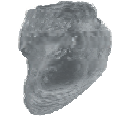

C4

Figure 8. Teeth of Acrodus spitzbergensis Hulke, 1873. (A) PMO 230.115, A1 - labial view, A2 - lingual view, A3 - occlusal view, A4 - mesio - distal view. (B) PMO 230.116, B1 - labial view, B2 - lingual view, B3 - occlusal view, B4 - mesio - distal view. (C) PMO 230.124, C1 - labial view, C2 - lingual view, C3 - occlusal view, C4 - mesio - distal view. Vendomdalen Member (Grippia bonebed), Vikinghøgda Formation, Lower Triassic (Spathian); Marmierfjellet, Spitsbergen.

root to PMO 230.115-16 is mesiodistally angled towards the central cone and gradually increase in apical height from the mesiodistal ends to the centre cone. The linguolabial grooves are both deep and apical concave. The root has irregular foramina positioned along the middle to upper part parallel with the linguo-labial groove. The linguo-labial grooves are deep and a nutrient groove positioned in the root to the right basally of the central cone (Fig. 8 A1).

\section{Acrodus oppenheimeri Stensiö, 1921 Figure 9}

Material: 16 teeth, well preserved and complete (except one tooth missing the root). 15 teeth are isolated and one is situated in a dolomitic matrix. The identified teeth are elongated with a large crushing surface. They range between a mesiodistal length of 3.1 to $11.5 \mathrm{~mm}$, apicobasal height of 2.7 to $5.6 \mathrm{~mm}$ and linguo-labial width of 1.6 to $3.9 \mathrm{~mm}$. The mesiodistal crown surface is approximately flat or slightly arching apically without any cusps/cusplets. The species resembles the A. gaillardoti in this study (PMO 230.120), but the distinct occlusal crest and the lack of linguo-labial crown bulging separate the species.

Description: A significant straight occlusal crest extends from the mesial to distal ends, but does not encounter the linguo-labial grooves. The vertical striations radiate apically in branches from the linguo-labial grooves to the occlusal crest. There are some short vertical striations located throughout the occlusal crest. The striations in the lingual crown centre, PMO 230.118 (Fig. 9 A1-4), (A2) are forming small circling structures as may indicate the central crushing part of the tooth. This area has slightly more elevated and coarser striations than the rest of the crown. The linguo-labial grooves have the same apical arching as the crown surface and they are linguo-labial deep. Both root and crown vary little in height throughout the mesiodistal length of the tooth. The root has randomly placed irregular foramina and the lingual sulcus is somewhat labial- concave, which results in a basal narrowing of the lingual root.

One of the smallest teeth identified of this species is PMO 230.119 (Fig. 9 B1-4). The labial crown is slightly broader than the lingual (Fig. $9 \mathrm{~B} 3$ ), which results in a small displacement of the occlusal crest, and it differs from PMO 230.118 that has a linguo-labial centred crest. It also has a more bulging crown (Fig. 9 B4) that may be a result of deeper linguo-labial grooves than PMO 230.118. The root of PMO 230.119 is significantly higher than the crown. It has large irregular foramina oriented in the labial root in central part from the mesial to distal end, while the apical labial root has a distribution of more rounded foramina (B1). In comparison to A. oppenheimeri in Stensiö (1921) that have apical concaved and elongated teeth, both PMO 230.118 and PMO 230.119 are flatter and smaller, which may indicate a different position in the jaw. Birkenmajer \& Jerzmanska (1979, plate 2 fig 7 \& 8) refers to an A. spitzbergensis tooth that is similar to PMO 230.118 with straight occlusal crest, but it differs from the A. spitzbergensis species described in this thesis by having a linguolabial flat crown with striations apically radiating to the mesiodistal straight occlusal crest. 
A1

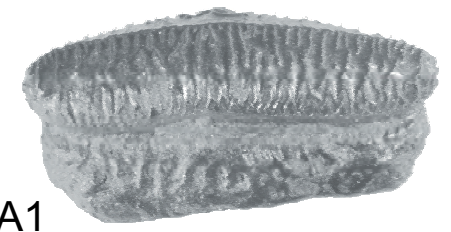

$\mathrm{A} 2$

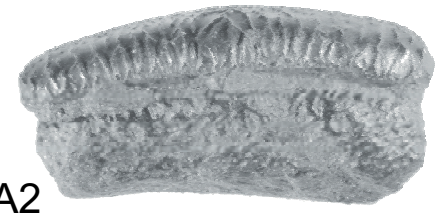

A3

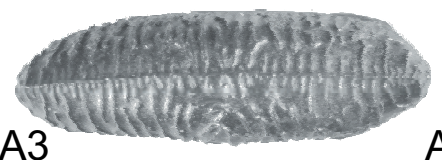

A4

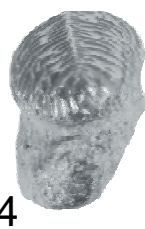

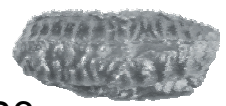

B3
B2

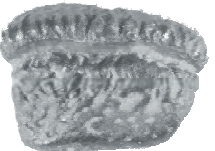

B1

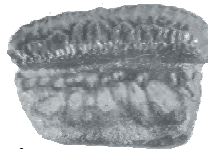

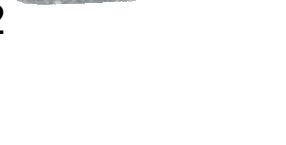

B4

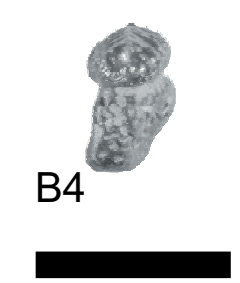

$5 \mathrm{~mm}$

Figure 9. Teeth of Acrodus oppenheimeri Stensiö, 1921. (A) PMO 230.118, A1 - labial view, A2 - lingual view, A3 - occlusal view, A4 mesio - distal view. (B) PMO 230.119, B1 - labial view, B2 - lingual view, B3 - occlusal view, B4 - mesio - distal view. Vendomdalen Member (Grippia bonebed), Vikinghøgda Formation, Lower Triassic (Spathian); Marmierfjellet, Spitsbergen.

\section{Acrodus lateralis Agassiz, 1839 \\ Figure 10}

Material: Six isolated teeth. The teeth are small, apicobasally flat and with an oval shaped crown. The striations radiate in the central part of tooth surface to the linguolabial grooves basally. They range between a mesiodistal length of 5 to $7.7 \mathrm{~mm}$, apico-basal height of 2.3 to $3 \mathrm{~mm}$ and linguo-labial width of 2 to $3.5 \mathrm{~mm}$.

Description: PMO 230.123 (Fig. 10 A1-4) has an elongated mesiodistal length, a crown which is oval, apical-concave and with an apical elevated central part. The elevated area is slightly mesiodistal offset to the right in labial view (Fig. 10 A1), whereas PMO 230.105 (Fig.
$10 \mathrm{~B} 1-4)$ central part is offset to the left. The occlusal crest fluctuates from the mesial to distal crown shoulder oriented in the labial side of the crown in occlusal view (Fig. 10 A3 \& B3). Several striations radiate from the occlusal crest basally to the crown shoulders, similar to A. lateralis described by Henz \& Hertel (2012) and Diedrich (2009, fig.6 4-5). The striations in A. lateralis described by Chrzastek (2008) are concentrated in the centre crown, and does not radiate basally to the crown shoulder. One of the identified teeth in this material (with only the crown preserved) has the same feature (PMO 230.144). The crown shoulders are rounded and the basal crown is apically angled towards the linguolabial grooves, creating a slight linguo-labial overhang over the root. The overhang is more prominent in PMO

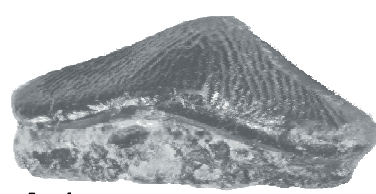

A1

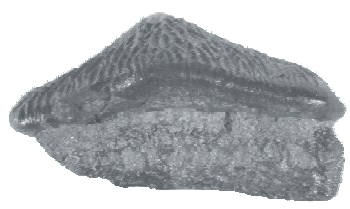

B1

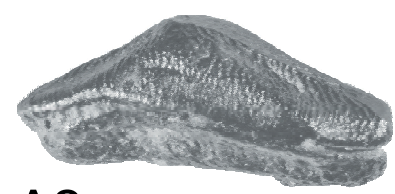

A2

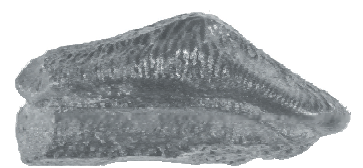

B2

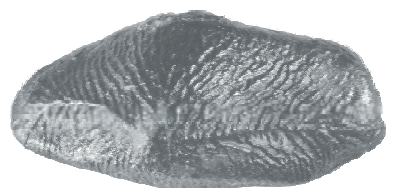

A3

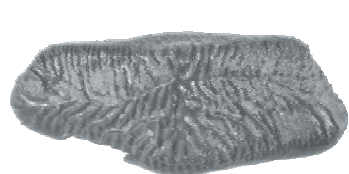

B3
A4
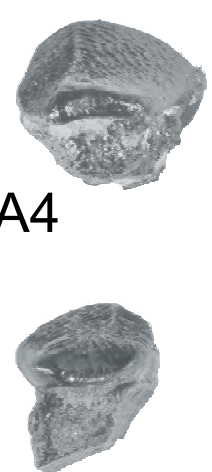

B4

\section{$5 \mathrm{~mm}$}

Figure 10. Teeth of Acrodus lateralis Agassiz, 1839. (A) PMO 230.123, A1 - labial view, A2 - lingual view, A3 - occlusal view, A4 - mesio distal view. (B) PMO 230.105, B1 - labial view, B2 - lingual view, B3 - occlusal view, B4 - mesio - distal view. Vendomdalen Member (Grippia bonebed), Vikinghøgda Formation, Lower Triassic (Spathian); Marmierfjellet, Spitsbergen. 
230.105 than in PMO 230.123. The linguo-labial grooves are deep. Few foramina observed in the labial root and the basal root is straight. The lingual root has a labial angled sulcus in the central part, while the mesiodistal end has a more vertically orientation. Both the crown and root are narrower in the left side, in labial view (Fig. 10 A1), compared to the right side. Böttcher (2015, fig. $8.5 \mathrm{a}-\mathrm{h}$ ) describes four A. lateralis teeth that differ greatly from PMO 230.123. Two of the teeth (fig. $8.5 \mathrm{a}-\mathrm{c} \& \mathrm{f}-\mathrm{g}$ ) have strongly apical concaved crown, which are more similar to PMO 230.105. The last two teeth (fig. $8.5 \mathrm{~d} \&$ e) show similarities with $A$. oppenheimeri, based mainly on the striations and flatter crown.

\section{Acrodus gaillardoti Agassiz, 1839 Figure 11}

Material: Identified 8 isolated teeth. They range between a mesiodistal length of 7.3 to $11.4 \mathrm{~mm}$, apico-basal height of 3.5 to $5.6 \mathrm{~mm}$ and linguo-labial width of 2.6 to 5.2 $\mathrm{mm}$. Some of the teeth are slightly fractured. The teeth are flat and elongated with a linguo labial bulging of the central crown. This species has not been described from Spitsbergen in earlier literature.

Description: PMO 230.120 (Fig. 11 A1-4) has the characteristic swelling of the crown at the left mesiodistal side in labial view (A1, A3), which may work as a larger crushing area, and a narrowing in opposite end. The occlusal crest continues weakly above the linguo-labial groove in mesiodistal direction, with slight linguo-labial fluctuations, to the apical crown surface. The vertical striations are coarse with relative large mesiodistal intervals. They radiate linguo-labial outwards from the swelled area to right above the linguo-labial groove on the crown shoulder. The labial groove is straight, as in the apical crown and basal root, and deep with some matrix. The lingual groove has slight fluctuations due to the swelling of the crown and matrix throughout the groove. The root is typical for those belonging to Acrodus by being apico-basal high, compared to the crown (Fig. 11 A1-2 \& A4). The labial root has a vertical nutrient groove oriented beneath the swelling part of the crown (Fig. 11 A1), while the entire root has several irregular foramina distributed disorderly. Beneath the swelling of the crown the lingual root is subsiding towards labial direction, which gives the sulcus a slight labial concavity. PMO 230.108 (Fig. 11 B1-4) is smaller than PMO 230.120 and with the swelling of the crown in the opposite direction, which may refer to opposite position in jaw or different upper/lower jaw position (Fig. 11 A \& B3).

\section{Acrodus sp. \\ Figure 12}

Material: Five isolated teeth, two of them nearly intact. The crowns are flat, oval, elongated and with no ornamentation or striations on the surfaces. Similarities to the species $A$. lateralis, but due to the flat and unornamented crown we speculate whether or not they are the same species. The identified teeth are small, elongated and ranging from an apico-basal height at $1.9 \mathrm{~mm}$ to 3.9 and a linguo-labial width of $1.5 \mathrm{~mm}$ to $2.6 \mathrm{~mm}$. Only two teeth have intact mesiodistal length, PMO 230.121 and PMO 230.122 with the lengths of 9.8 $\mathrm{mm}$ and $7.4 \mathrm{~mm}$ respectively.

Description: The crown is very brittle with several disorderly oriented fractures. PMO 230.121 (Fig. 12 A1-4) has a bulging labial crown with a slight skewness of the maximal linguo-labial width and apico-basal

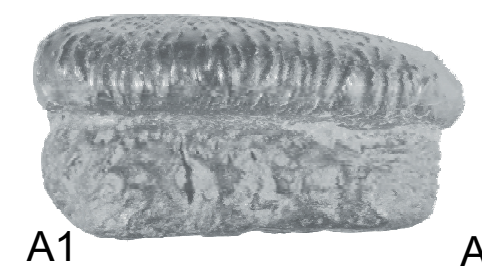

A1

A2

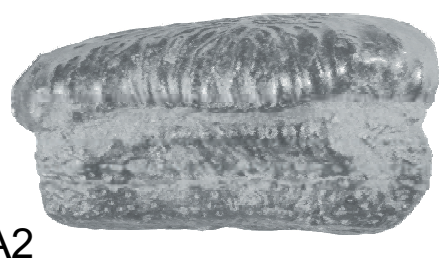

A3

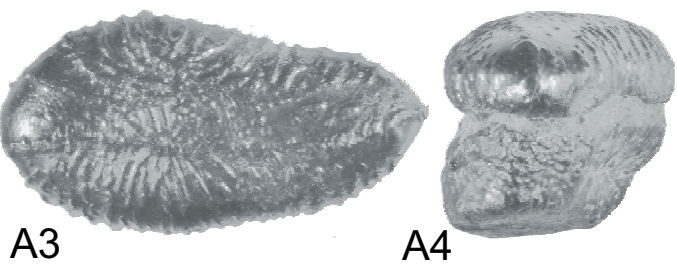

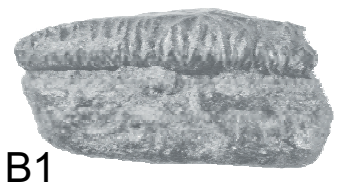

B2

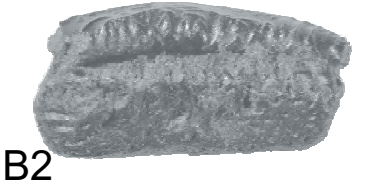

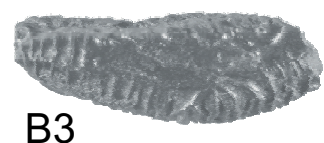

B4

B3

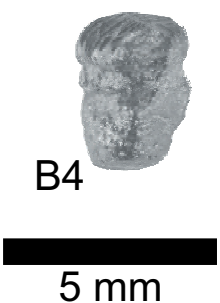

Figure 11. Teeth of Acrodus gaillardoti Agassiz, 1839. (A) PMO 230.120, A1 - labial view, A2 - lingual view, A3 - occlusal view, A4 - mesio distal view. (B) PMO 230.108, B1 - labial view, B2 - lingual view, B3 - occlusal view, B4 - mesio - distal view. Vendomdalen Member (Grippia bonebed), Vikinghøgda Formation, Lower Triassic (Spathian); Marmierfjellet, Spitsbergen. 


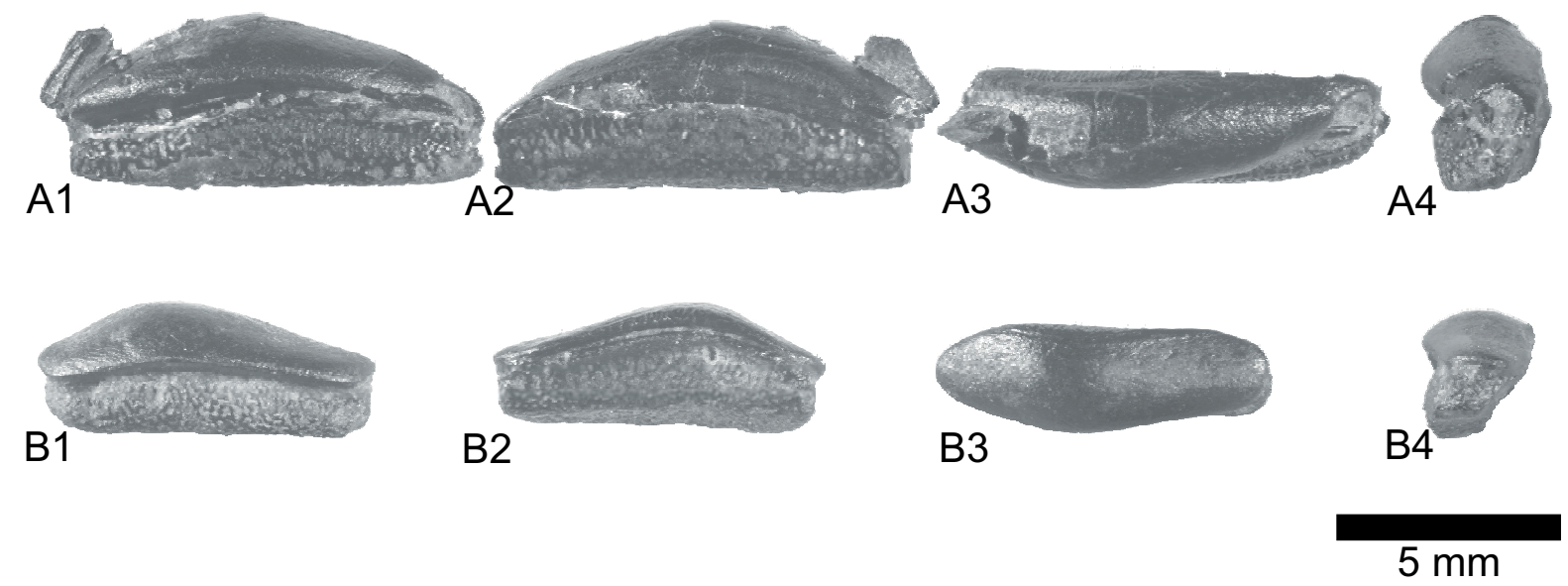

Figure 12. Teeth of Acrodus sp. (A) PMO 230.121, A1 - labial view, A2 - lingual view, A3 - occlusal view, A4 - mesio - distal view. (B) PMO 230.122, B1 - labial view, B2 - lingual view, B3 - occlusal view, B4 - mesio - distal view. Vendomdalen Member (Grippia bonebed), Vikinghøgda Formation, Lower Triassic (Spathian); Marmierfjellet, Spitsbergen

height to the left in both labial (A1) and occlusal view (A3), while the lingual crown is straight. The crown is slightly concave in apical direction, which also reflects in the concavity of the lingual groove. PMO 230.122 (Fig. 12 B1-4) is smaller with a flatter crown than PMO 230.121. The crown shoulder to PMO 230.122 has an angular edge that is apical angled inwards to the centre of the root, which results in an 'overhang' of the crown. The upper part of the root has a distinct edge, which serves as the end of the root and beginning of the lingual groove. Beneath the distinct edge, the root falls inward in an angle that gives the lingual root a concave shape in labial direction. A fluctuation of the labial groove in PMO 230.121 results in an alteration of the root height. The foramina are disorderly distributed and covers most of the root surface both labially and lingually. The root base is straight.

\section{Palaeobates polaris Stensiö, 1921 Figure 13}

Material: Three isolated teeth. The teeth are small with an angular central crown, and coarse striations fill the entire crown. Only two teeth have the mesiodistal length preserved, 6.3 and $7.3 \mathrm{~mm}$, while the apico-basal heigth range from $2.4 \mathrm{~mm}$ to $3.7 \mathrm{~mm}$ and linguo-labial width range from $2.1 \mathrm{~mm}$ to $2.4 \mathrm{~mm}$. Romano \& Brinkmann (2010) presented a Palaeobates polaris model were they reconstructed the lower jaw and palatoquadrate dentition from material preserved in situ. The dentition files were divided in numbers from anterior to posterior position, respectively from M0 to M7 and P0-P6. The teeth described in this study belongs to the anterior file P1 (Romano \& Brinkmann, 2010, fig. 3. C4).

Description: The mesiodistal crown surface to PMO 230.134 (Fig.13 A1-4) is apical angled towards the crown top (A1) and is narrower in the mesiodistal ends than in the central crown (A3), similar to Stensiö (1921: plate 3 , fig. 15 , and pers.obs. J.B.). The occlusal crest is continous through the mesiodistal elongation of the crown, through the central apical top, and ends by the mesiodistal crown shoulders. A distinct labial transverse crest starts apically from the labial groove and encounters the occlusal crest at the central apex (Fig. 13 A3). Coarse striations are disorderly oriented on the surface and apically radiates from the linguo-labial crown shoulder

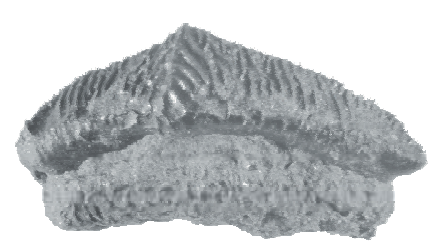

A1

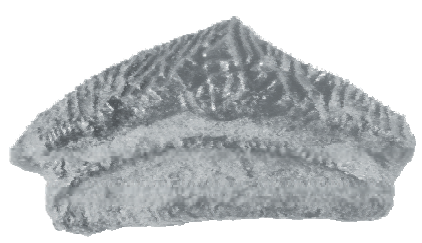

A2

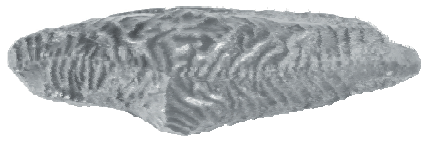

A3

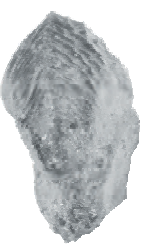

A4

$5 \mathrm{~mm}$

Figure 13. (A) Tooth of Palaeobates polaris Stensiö, 1921. PMO 230.134, A1 - labial view, A2 - lingual view, A3 - occlusal view, A4 - mesio distal view. Vendomdalen Member (Grippia bonebed), Vikinghøgda Formation, Lower Triassic (Spathian); Marmierfjellet, Spitsbergen. 
to the occlusal and transverse crests. Both the linguolabial grooves are distinct (Fig. 13 A1 \& 2). The labial root is significantly apico-basally higher than the lingual root (Fig. 13 A1 \& 2), with several irregular foramina, and the sulcus is labially concave, which results in a basal narrowing of the root.

\section{Lissodus angulatus (Stensiö, 1921) Figure 14}

Material: One isolated tooth (PMO 230.125).

Description: PMO 230.125 (Fig. 14 A1-4) is a small and nearly intact tooth with a labial tilting of the crown, but still larger than the teeth described by Stensiö (1921) that has a mesiodistal length of $1.5-2 \mathrm{~mm}$ and apicobasal height of $0.5-0.75 \mathrm{~mm}$. The teeth described by Blazejowski (2004) have similar size, with a mesiodistal length up to $7 \mathrm{~mm}$. The crown has a large central cusp with distinct vertical and occlusal crests, which apical meets the tip in a sharp point (Fig. 14 A3). The occlusal crest extends nearly from the linguo-labial groove in mesiodistal direction through the apical peak of each cusp (Fig. 14 A1 \& A4). The central cusp has a lingual swelling named the lingual peg with the transverse crest radiating through the center and down to the longitudinal crest. The longitudinal crest is distinct and extends mesiodistally. There are a few lingual striations on the crown while the rest of the crown is smooth. One lateral cusplet is located on each side of the central cusp. This differs from the teeth described by Blazejowski (2004) that have incipient cusplets rather than welldeveloped cusplets. The lateral cusplet may indicate an anterior position in the jaw (Blazejowski, 2004). The crown is linguo-labially thicker to the right in labial view (Fig. $14 \mathrm{~A} 1$ ) than to the left where there is less swelling of the cusplet (Fig. 14 A3). The mesiodistal crown shoulders are rounded and pinch out beyond the mesiodistal root. The height of the root is decreasing to the left in labial view (Fig. $14 \mathrm{~A} 1$ ) and the basal root is flat. Irregular foramina are disorderly distributed in the root.

\section{Hybodontoidea basal plate of a cephalic spine Figure 15}

Material: One fractured basal plate of a cephalic spine (PMO 230.142).

Description: PMO 230.142 (Fig. 15 A1-4) has both the central and lateral lobe preserved; the rest of the basal plate is missing along with the spine. The basal plate has a mesiodistal length of $24.6 \mathrm{~mm}$, apico-basal height of $16.4 \mathrm{~mm}$ and a linguo-labial width of $9.5 \mathrm{~mm}$. The spine attachment surface is identifiable as a distinct scar on the top of the basal plate (Fig. 15 A2). The scar is significantly larger than in the basal plate found by Stensiö (1921: plate 1, fig. 11a \& $\mathrm{b}$ and pers.obs. J.B.). In front of the bending basal plate (Fig. $15 \mathrm{~A} 1$ ) towards the attachment

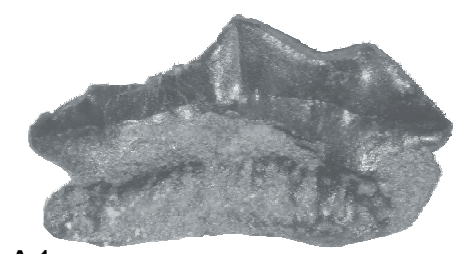

A1

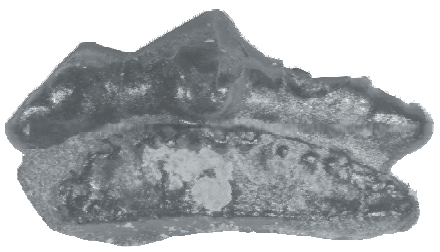

A2

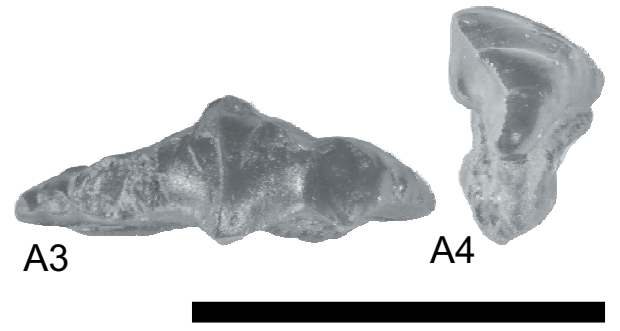

$5 \mathrm{~mm}$

Figure 14. (A) Tooth of Lissodus angulatus (Stensiö, 1921). PMO 230.125, A1 - labial view, A2 - lingual view, A3 - occlusal view, A4 - mesio - distal view. Vendomdalen Member (Grippia bonebed), Vikinghøgda Formation, Lower Triassic (Spathian); Marmierfjellet, Spitsbergen.

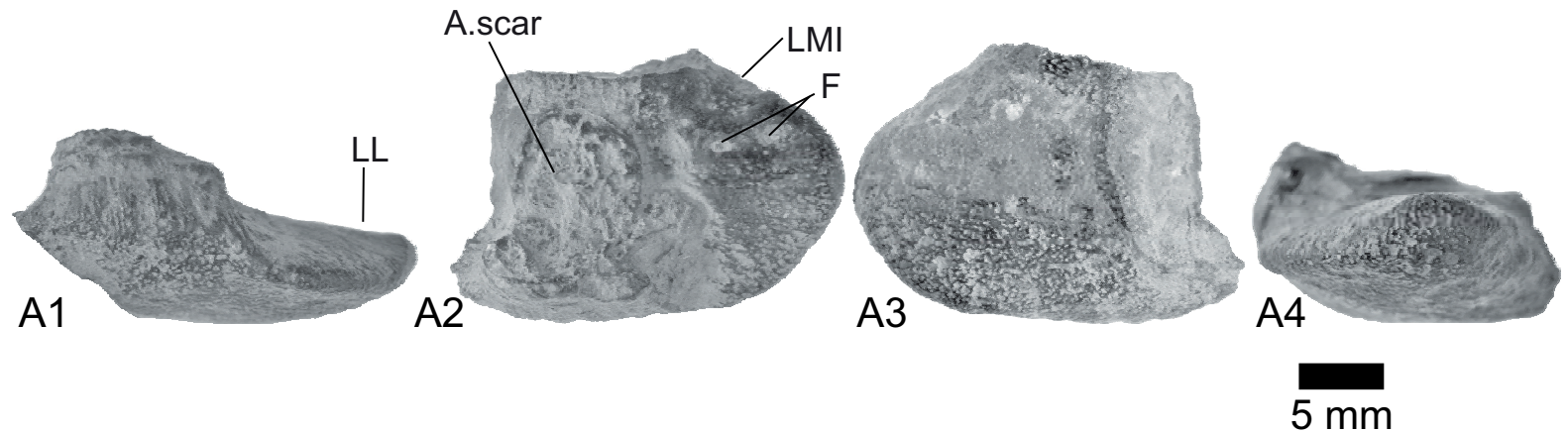

Figure 15. (A) Basal plate of a Hybodontoid cephalic spine. PMO 230.142, A1 - Anterior view, A2 - superior view, A3 - basal view, A4 left lateral - view. Vendomdalen Member (Grippia bonebed), Vikinghøgda Formation, Lower Triassic (Spathian); Marmierfjellet, Spitsbergen. A.scar - scar for spine attachment, F-foramina, LMI - lateral margin indentation, LL - lateral lobe. 
surface, there are deep grooves oriented in vertical direction. The lateral lobe end is rounded and slightly bent in apical direction. It has two large foramina near the lateral margin indentation. The rest of the basal plate is filled with small irregular to semi rounded pores. The plate is, with some exception, covered in black enamel (Fig. $15 \mathrm{~A} 3$ ). Because of the disarticulated preservation, the species of the basal plate is difficult to determine.

\section{Hybodontoidea fin spine (1) Figure 16}

Material: One almost complete fin spine and one apical fragment.

Description: PMO 230.139 (Fig. 16 A1-6) is elongated and gently curved posteriorly and right laterally with a mesiodistal length of $51.7 \mathrm{~mm}$, apico-basal height of 12.9 $\mathrm{mm}$ and an anterior broadness of $6.6 \mathrm{~mm}$. The spine is an distal part of a fin spine with a missing apical tip and basal part. In cross-section, the spine is rounded to eggshaped (Fig. 16 A6). The wideness narrows significant from the basal to apical side (Fig. 16 A1 \& 2). Both lateral and anterior surfaces have coarse longitudinal striations (better referred to as ribs) distributed in regular intervals and covered with black enamel (Fig. 16 A1, 2 \& 3). The ribs and the surface have approximately the same broadness and extend between them from the basal to apical part of the fin spine. The ribs meet in the apical top edge due to the narrowing in apically direction. Blunt, broken, denticles occur on the posterior edge with one series oriented in a footprint pattern (Fig. 16 A4). There are 16 denticles.

PMO 230.139 is equal to the fin spine in Stensiö (1921: plate 1 fig. 17 and pers.obs. J.B.), but is more fragmented. They both have the same interval between the coarse striations and the same pattern of the denticles. The lateral wider and anterior broader PMO 230.139 indicates a possible mesiodistal longer fin spine than the one described by Stensiö.

\section{Hybodontoidea fin spine (2) Figure 17}

Material: One fin spine (PMO 230.140).

Description: PMO 230.140 (Fig. 17 A1-6) is a massive fin spine, gently curved both laterally and posteriorly towards the apical tip. The spine has a mesiodistal length of $35.2 \mathrm{~mm}$, a lateral width of $19.5 \mathrm{~mm}$ and an anterior broadness of $9.7 \mathrm{~mm}$. This spine is probably an upper middle part, an observation supported by the missing apical tip (Fig. $17 \mathrm{~A} 1$ ) and the start of the posterior basal opening (Fig. 17 A4). The cross-section of the spine has a rounded to diamond-shape that is more longitudinal than latitudinal (Fig.17 A6). The lateral sides are without coarse ornamentation and have rather gentle vertical
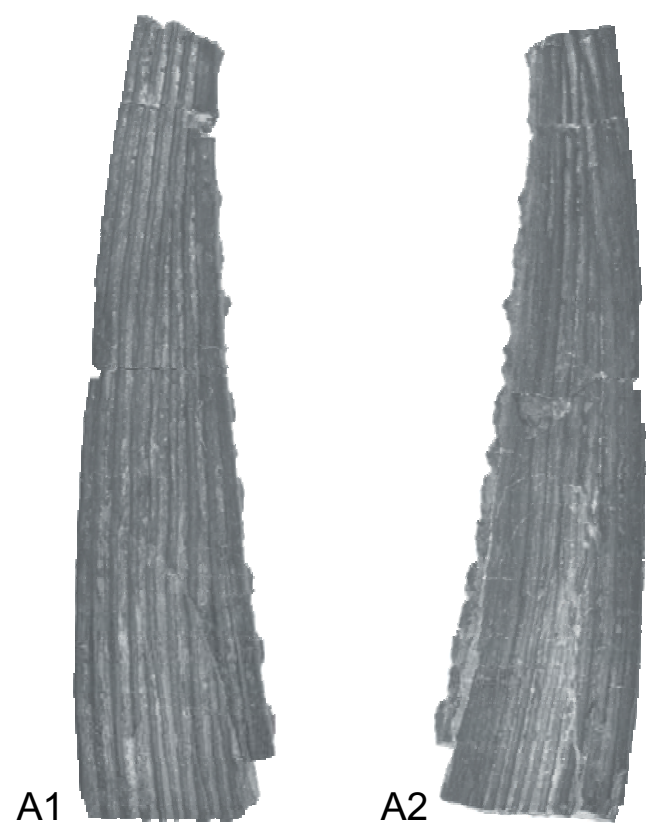
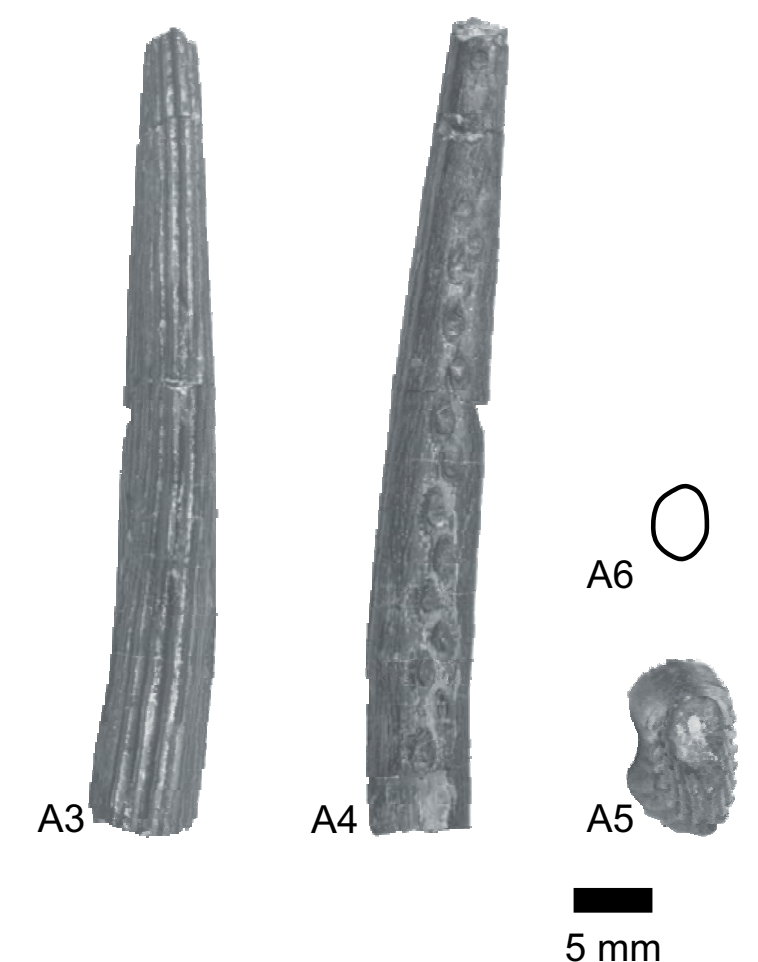

Figure 16. A Hybodontidea sp. fin spine (1). (A) PMO 230.139, A1 - Left lateral view, A2 - Right lateral view, A3 - Anterior view, A4 Posterior view, A5 - superior view, A6 - Illustration of cross section (A5). Vendomdalen Member (Grippia bonebed), Vikinghøgda Formation, Lower Triassic (Spathian); Marmierfjellet, Spitsbergen. 
striations. The right-lateral side has almost entirely lost the enamel and is covered with matrix (Fig. 17 A2). Two thirds of the posterior wall consists of the same gentle vertical striations as the lateral sides while the last part starts with the basal opening (Fig. 17 A4), which is deep with thick lateral walls extending on each side. The anterior wall has eight blunt denticles, where six of them are oriented in a vertical line (Fig. 17 A3) and covered with black enamel.

Stensiös hybodont fin spine (1921: plate 1 fig. 18a \& b and pers.obs. J.B.) is similar to PMO 230.140 by having the same soft vertical striations, same proportion of the lateral widths and identical cross-sections. The PMO 230.140, however, differs from the spine described by Stensiö (1921) by being smaller, with different orientation of the denticles and by having a posterior basal opening. The presence or absence of the basal opening could be an outcome of differences between first and second dorsal fin spine (Cione et al., 2002).

\section{Synechodontiformes Duffin \& Ward, 1993}

Synechodontiformes are placed in the Neoselachii as they have three layered enameloid (SCE and BCE units), and teeth that are of the cutting-clutching or cutting sensu stricto type, whereas the hybodontiformes rarely have cutting dentition (Cappetta, 1987) and mostly only one layer (SCE) enameloid (Enault et al., 2015).

\section{Synechodontiformes sp. (1) Figure 18}

Material: 36 isolated teeth. Neoselachian teeth have not been described from Spitsbergen before. Most of the teeth are fragmented with only the central part preserved, the teeth have a dominant and high central cusp with no or few lateral cusplets. The crown is high while the root is less dominant. They range from a mesiodistal length of 7.2 to $11.3 \mathrm{~mm}$, apico-basal height of 3.2 to $7.3 \mathrm{~mm}$ and linguo-labial width of 1.6 to $3.9 \mathrm{~mm}$.

Description: The central cusp of PMO 230.128 is located in the mesiodistal centre, while the central cusp is bent to the right in mesiodistal view (Fig. $18 \mathrm{~B}-\mathrm{D} 1$ ) for PMO 230.110-1 and PMO 230.129 (Fig. 18 D1-3) and slightly lingually. The crown surface is smooth and unornamented except for the occlusal crest and a few transverse crests radiating apically from the linguolabial grooves. The occlusal crest extends from mesial and distal ends to the apex of the central cusp and forms a sharp cutting edge, which is apically broader at the base of the central cusp base. PMO 230.128 (Fig. 18 A1-4) has an apico-basal high central cusp with a conical shape and two broken lateral cusplets on each side, and thus resembles the teeth of Mucrovenator minimus (Cuny et al., 2001). The labial crown shoulder is distinct with a longitudinal sharp edge, which is rounded in the mesiodistal ends (Fig. $18 \mathrm{~A} 1$ ). It differs from Mucrovenator minimus that has no groove separating the crown and root.

PMO 230.110 (Fig. 18 C1-4) differs from PMO 230.128 and PMO 230.111 (Fig. 18 B1-4) by having no visible cusplets. Labial and lingual grooves are concave in apical direction, the labial groove is high, resulting in

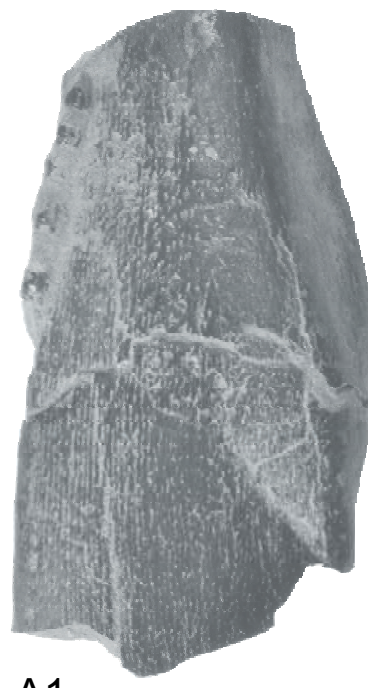

A1

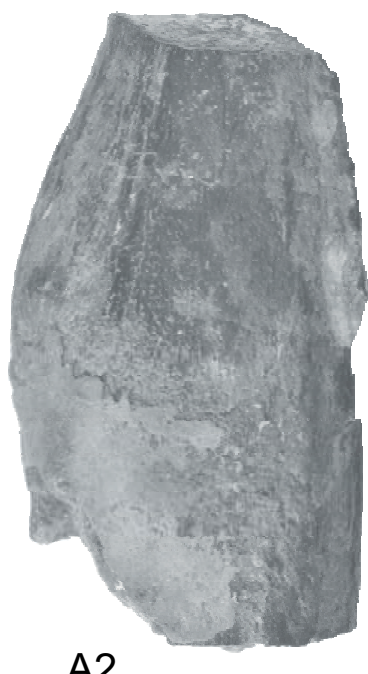

A2
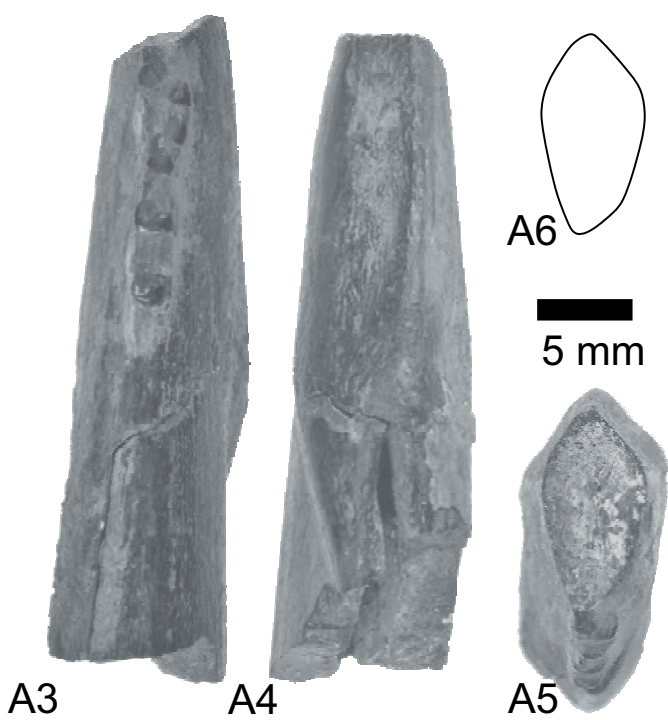

Figure 17. (A) Hybodontidea sp. fin spine (2). PMO 230.140, A1 - Left lateral view, A2 - Right lateral view, A3 - Anterior view, A4 Posterior - view A5 superior - view. A6 Illustration of cross section (A5). Vendomdalen Member (Grippia bonebed), Vikinghøgda Formation, Lower Triassic (Spathian); Marmierfjellet, Spitsbergen. 


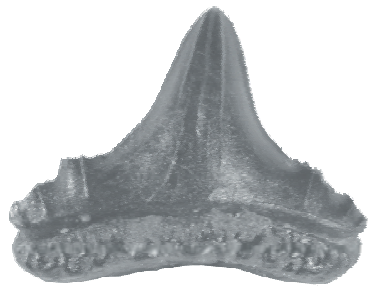

A1

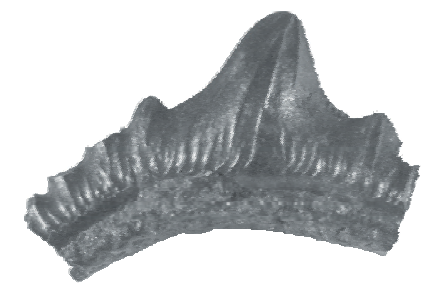

B1

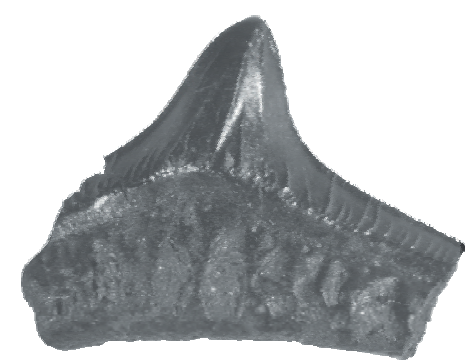

C1

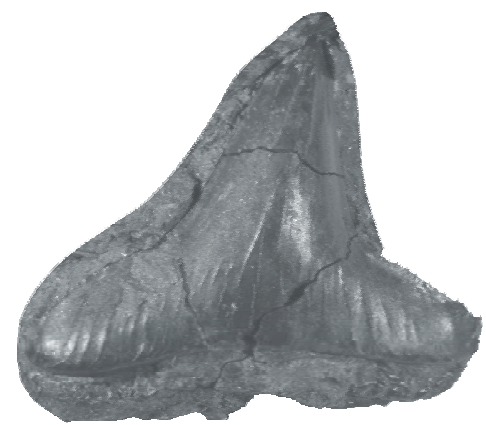

D1

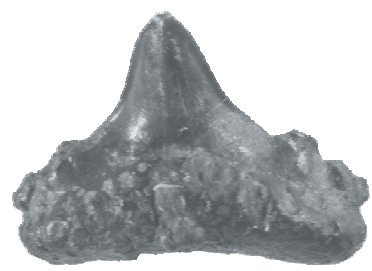

A2

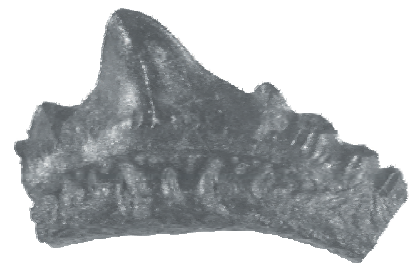

B2

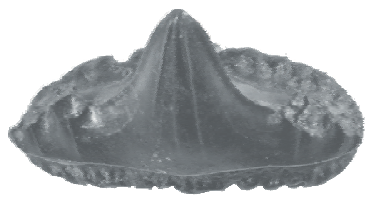

A3

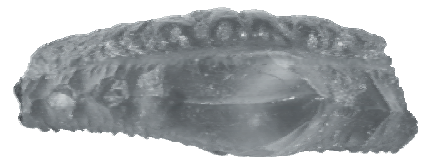

B3

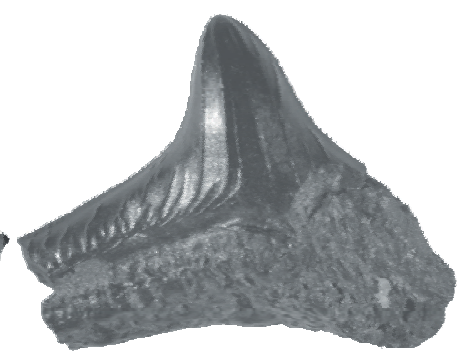

C2
C3

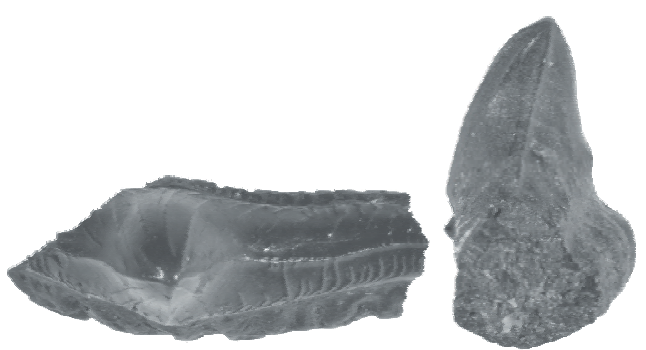

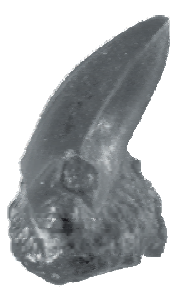

A4

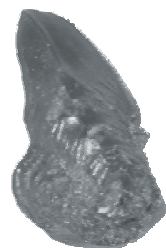

B4

C4

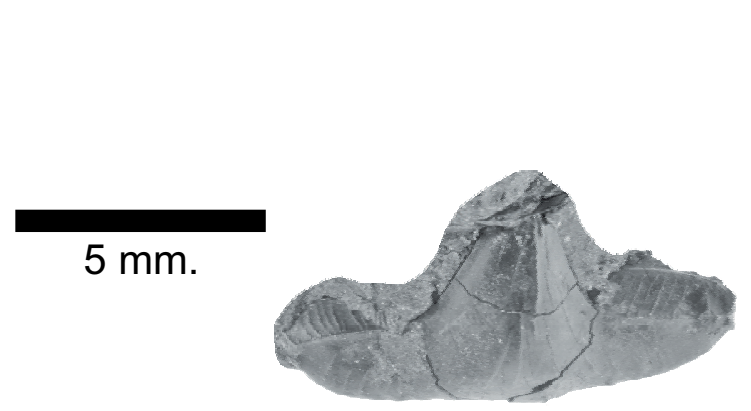

D2

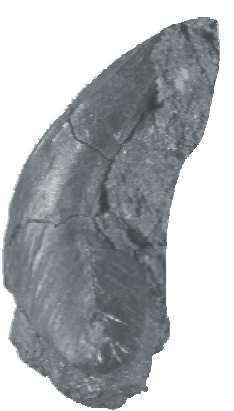

D3

Figure 18. Teeth of Synechodontiformes sp. (1). (A) PMO 230.128, A1 - labial view, A2 - lingual view, A3 - occlusal view, A4 - mesio - distal view. (B) PMO 230.111, B1 - labial view, B2 - lingual view, B3 - occlusal view, B4 - mesio - distal view. (C) PMO 230.110, C1 - labial view, C2 - lingual view, C3 - occlusal view, C4 - mesio - distal view. (D) PMO 230.129, preserved in matrix, D1 - labial view, D2 - occlusal view, D3 - mesio - distal view. Vendomdalen Member (Grippia bonebed), Vikinghøgda Formation, Lower Triassic (Spathian); Marmierfjellet, Spitsbergen.

an interval between crown and root while the lingual is more concave and appears as a line. The labial grooves have equal mesiodistally thicknesses, with exception of PMO 230.110 where the labial root apically extends under the central cusp, as Acrodus. Both the linguo-labial grooves are deep and apically concave with a smooth surface. The linguo-labial roots have irregular foramina distributed disorderly and PMO 230.110 with two large irregular foramina (nutrient grooves) oriented in apicobasal direction in the centre mesiodistal root (C3).

\section{Synechodontiformes sp. (2) Figure 19}

Material: 13 teeth, 12 isolated and one in matrix. This tooth morphology has not previously been described from Spitsbergen. The teeth range between a mesiodistal length of 4.7 to $11.2 \mathrm{~mm}$, apico-basal height of 1.5 to $4.6 \mathrm{~mm}$ and linguo-labial width of 1.1 to $3.3 \mathrm{~mm}$. The Synechodontiformes sp. (2) differs from Synechodontiformes sp. (1) by a less dominant central 
cusp, more elongated cutting edge and higher apico basal root.

Description: The central mesiodistal crown meets in a cutting edge with both the cusp and cusplets. The crown has a triangulated shape in cross-section (Fig. 19 A-C4). PMO 230.127 (Fig. 19 A1-4) has an elevated central cusp with five small lateral cusplets on each side. PMO 230.126 (Fig. 19 B1-4) is similar to PMO 230.127, but has a crown with a less distinct central cusp, smaller cusplets and more mesiodistal elongation. To the left of the central cusp there are two intact lateral cusplets (smaller version) of the cusplets in PMO 230.127, while to the right there is 10 to 11 lateral cusplets (Fig. 19 B1). The right cusplets look more like small elevations of the crown instead of separate cusplets, better defined as sub-cusplets. PMO 230.117 (Fig. $19 \mathrm{C} 1-4)$ differs from the others by having a pointier and more distinct cusp, resembling slightly the A. spitzbergensis central cusp. The occlusal crest emerges from the mesiodistal crown shoulders and continues throughout the cutting edge as a sharp line. Striations radiates apically from the linguo-labial grooves on the crown shoulder, creating furrows. Fewer vertical striations continue apically to the apexes of the cusp and cusplets. The crown is linguo-labial narrower than the root, and is oriented slightly labially. The linguolabial grooves are distinct, shallow, forming an apicobasal interval between the basal crown and apical root, and appear as a smooth black area. In the root beneath the central cusp, there are large irregular foramina that extend from the basal root to the labial groove. The lingual root is short with a distinct basal edge that forms the start of the sulcus, which are angled approximately 45 degrees from the cutting edge (A-C 4).

\section{Nemacanthus Agassiz, 1837 \\ Nemacanthus fin spines}

Figure 20

Material: Three fragments of fin spines.

Description: The specimen PMO 230.141 (Fig. $20 \mathrm{~A} 1-5)$ is a small spine fragment assumed to be the middle section of a fin spine based on the Nemacanthus splendens described by Böttcher (2015). The fin spine has a mesiodistal length of $13.5 \mathrm{~mm}$, a lateral width of $7.8 \mathrm{~mm}$ and an anterior broadness of 3.3 $\mathrm{mm}$. In cross section, the fin spine has an oval shape and a possible nutrient canal is oriented in the centre (Fig. 20 A4 \& 5). The anterior ridge is defined by distinct, dark and smooth enamel with some surface fractures (Fig. 20 A3). The lateral side has up to five longitudinal rows of small tubercles oriented vertically parallel to each other and is continuous basally from apical fracturing point to the angled start of the basal fin spine. The longest rows have nine to ten tubercles. The tubercles are oval to sub rounded and consist of black enamel which slightly extends from the surface (Fig. 20 A1 \& 2). Some of the tubercles are missing the black surface enamel and are then either grey or a mix of grey and black. The basal part of the fragments are characterized by an angular grey surface tilting towards the anterior side (Fig. 20 A1) with vertical striations oriented parallel to the black anterior ridge, which is similar to the Nemacanthus splendens in Böttcher (2015, fig. $8.12 \mathrm{a}-\mathrm{d})$. The angular grey surface is not present in the remodelling of Nemacanthus monilifer in Storrs (1994, fig. 3J), which may exclude PMO 230.141 affinities to that species. The fin spine resembles the "Generically indeterminable selachian; fin spine" in Stensiö (1921, plate 1 fig. 19a \& b and pers.obs J.B.).
A1
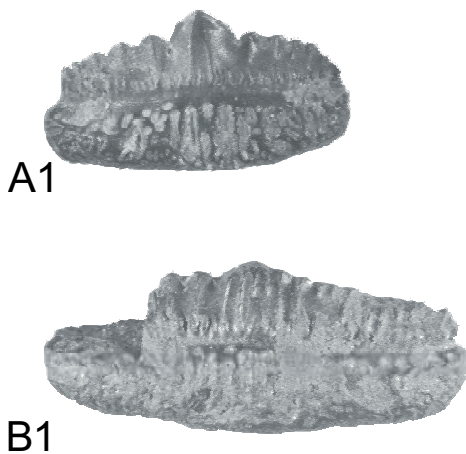

B1

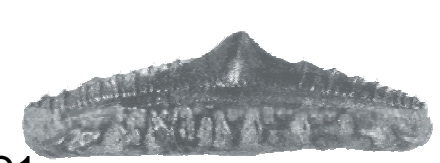

C1 1

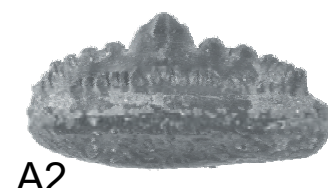

A2

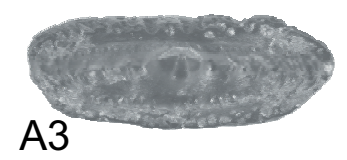

A4
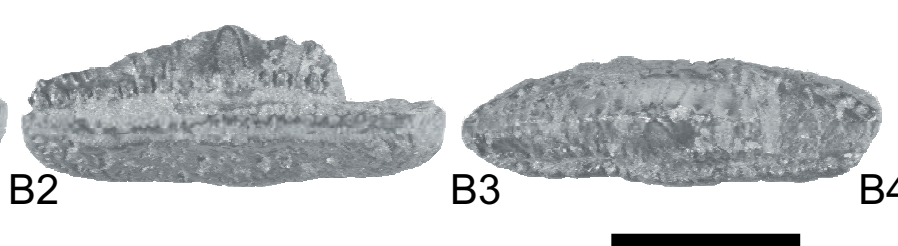

B4

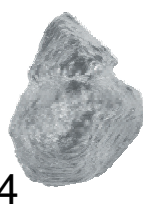

$5 \mathrm{~mm}$
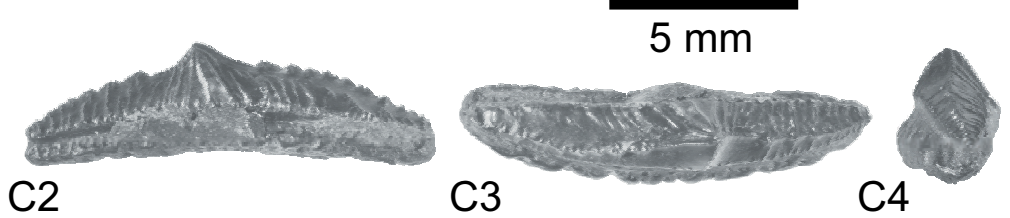

Figure 19. Teeth of Synechodontiformes sp. (2). (A) PMO 230.127, A1 - labial view, A2 - lingual view, A3 - occlusal view, A4 - mesio - distal view. (B) PMO 230.126, B1 - labial view, B2 - lingual view, B3 - occlusal view, B4 - mesio - distal view. (C) PMO 230.117, C1 - labial view, C2 - lingual view, C3 - occlusal view, C4 - mesio - distal view. Vendomdalen Member (Grippia bonebed), Vikinghøgda Formation, Lower Triassic (Spathian); Marmierfjellet, Spitsbergen. 

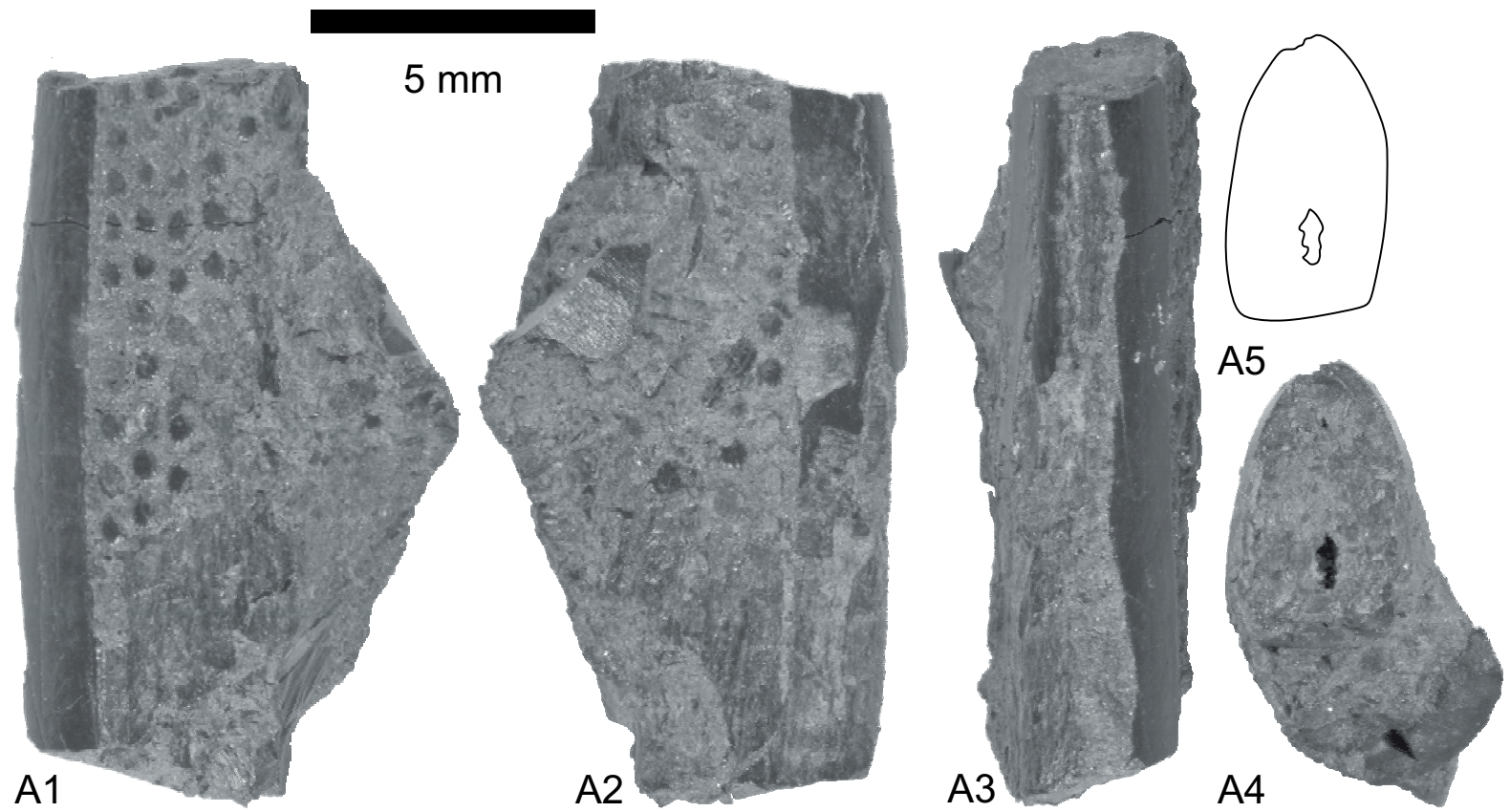

Figure 20. (A) Nemacanthus sp. fin spine. PMO 230.141, A1 - Left lateral view, A2 - Right lateral view, A3 - Anterior view, A4 superior - view. A5 Illustration of cross section (A4). Vendomdalen Member (Grippia bonebed), Vikinghøgda Formation, Lower Triassic (Spathian); Marmierfjellet, Spitsbergen.

\section{Enameloid microstructure}

The chondrichthyan tooth enamel is characterized by two units. The outer homogenous Single Crystallite Enameloid (SCE), where the crystallites have no preferred orientation, and the inner Bundled Crystallite Enameloid (BCE), where the crystallites forms bundles (Enault et al., 2015). The BCE unit is further divided in three different components: Parallel Bundled Enameloid (PBE), Tangled Bundled Enameloid (TBE) and Radial Bundled Enameloid (RBE), where their terminology is based on the crystallites orientation (Enault et al., 2015; and Fig. 2 for nomenclature explanation).

The teeth are less acid resistant near the center part of tooth, which results in the inner surface to be more affected by the acid than the outer surface.

Acrodus spitzbergensis (PMO 230.334, Fig. 21 A1-3): The enamel average range in apico-basal height from $130 \mu \mathrm{m}$ at the linguo-labial sides to $280 \mu \mathrm{m}$ at the occlusal crest and is recognizable by two layers of SCE. The first layer consist of homogeneous crystallites with none preferred orientation and the second is defined by canals mostly elongated perpendicular to the dentine boundary, most likely due to foramina (dental tubules) (Fig. 21 A2 \& A3). These canals are mainly located from the linguo-labial crown shoulder apical to the crown top. The contact between the dentine and enameloid is unclear due to the intermingled tissues (Fig. $21 \mathrm{~A} 2$ ).

Acrodus scaber (PMO 230.109, Fig. 21 B1-3): The enamel comprises two layers of SCE and range in apico- basal height from 210 to $350 \mu \mathrm{m}$, separated by different orientation of the crystallites (Fig. 21 B2 \& 3). The layers are oriented as those in A. spitzbergensis, however, the boundary between the dentine and enameloid is more distinct (Fig. 21 B2). It has thick enamel, compared to A. scaber, throughout the whole cross section with a slight narrowing towards the linguo-labial grooves.

Polyacrodus sp. (PMO 230.131, Fig. 21 C1-3): The enamel is comprised of two layer of SCE, as in A. scaber and A. spitzbergensis, with an apico-basal range of 54 to $97 \mu \mathrm{m}$ and oriented in the same way as the Acrodus teeth (Fig. $21 \mathrm{~B} 1-3)$. The outer homogenous layer is thicker than the inner layer with perpendicular oriented crystallites at the linguo-labial crown sides while at the occlusal crest the inner layer expand to almost the same apico-basal height, similar to what was observed by Cuny et al. (2001). The cross section of Polyacrodus sp. differs from the other investigated species by having a distinct pulp cavity (Fig. $21 \mathrm{C} 1$ ). The pulp cavity has been filled by calcite crystallites based on quantitative chemical analyse.

Synechodontiformes sp. (2) (PMO 230.126, Fig. 22 A1-3): The species has the same structure of the enamel as Synechodontiformes sp. (1). The SLE layer range with an apico-basal height at $61 \mu \mathrm{m}$ at the crown shoulders to $90 \mu \mathrm{m}$ at the occlusal crest. The RBE is little present both in the untreated and acid treated surface, opposite to Synechodontiformes sp. (1).

Synechodontiformes sp. (1) (PMO 230.335, Fig. 22 B1-4): The outer SLE layer is similar with the homogenous layer of none preferred orientation of the crystallites and the 

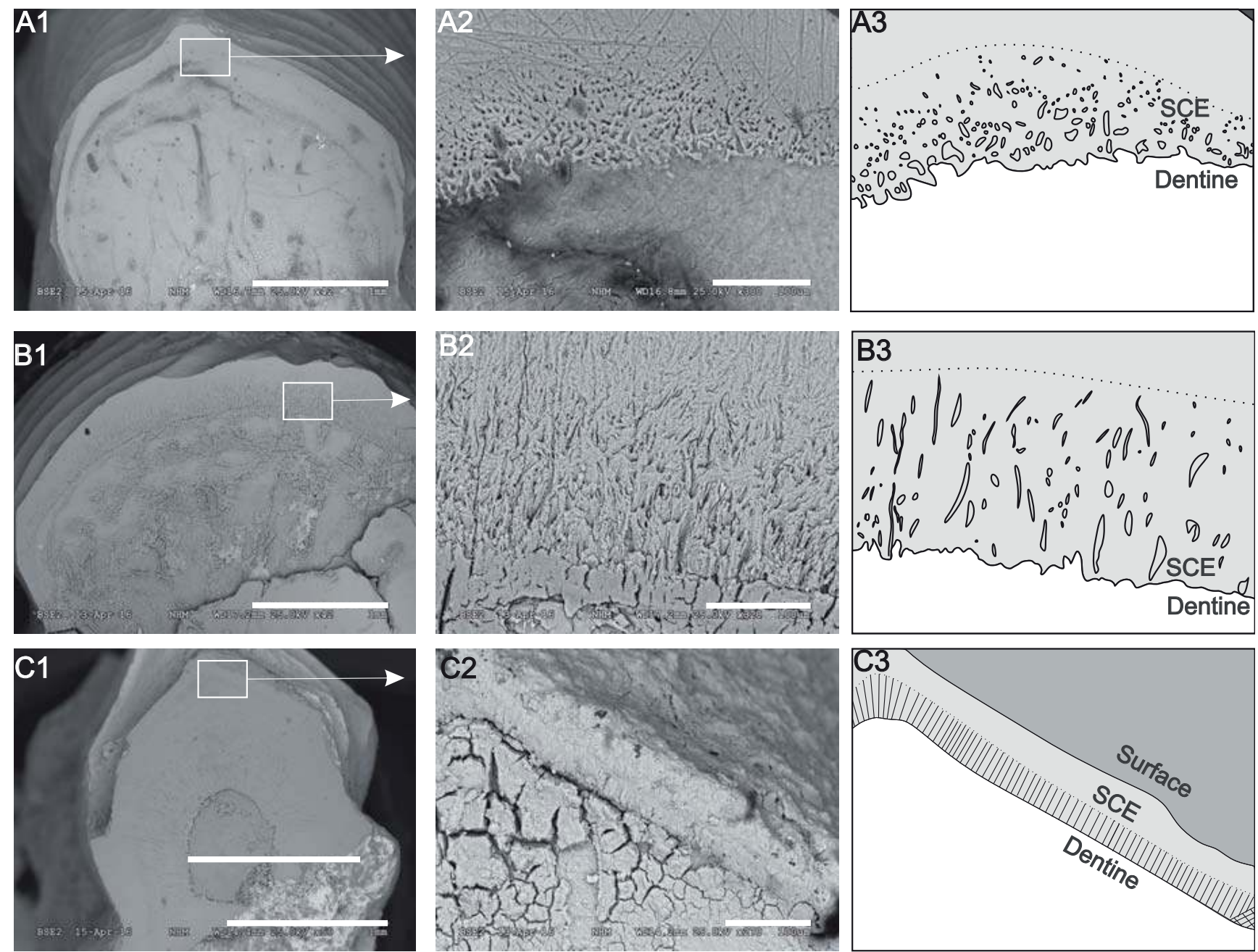

Figure 21. Tooth enameloid microstructure of: (A) Acrodus spitzbergensis, PMO 230.334: A1 - Cross section of the tooth perpendicular to its mesio-distal axis. Scale bar $1 \mathrm{~mm}$. A2 - Section by the occlusal crest. Scale bar $100 \mu \mathrm{m}$. A3 - Interpretation of A2. (B) Acrodus scaber, PMO 230.109: B1 - Cross section of the tooth perpendicular to its mesiodistal axis. Scale bar $1 \mathrm{~mm}$. B2 - Section by the labial side of the occlusal crest. Scale bar $100 \mu \mathrm{m}$. B3 - Interpretation of B2. (C) Polyacrodus sp. PMO 230.131: C1 - Cross section of the tooth perpendicular to its mesiodistal axis. Scale bar $1 \mathrm{~mm}$. C2 - Section by the labial side of occlusal crest. C3 - Interpretation of C2. Scale bar $100 \mu \mathrm{m}$. See Table 2 for SEM preparations and parameters. SCE - single crystallite enameloid.

parallel oriented crystallites layer towards the dentine surface as in Acrodus, Hybodus and Polyacrodus (Fig. 22 B2 \& 3). The SLE layer range in apico-basal height from 98 to $166 \mu \mathrm{m}$. In addition, the enamel has RBE extending from the outer SLE approximately perpendicular to the dentine surface (Fig. 22 B2 \& 3). This feature is best presented in the untreated cross-section (Fig. 22 B2), while the acid treated surface indicates the transition between the possible PBE layer $(\sim 98 \mu \mathrm{m})$ and dentine (Fig. 22 B4).

Hybodus rapax (1) (PMO 230.143, Fig. 22 C1 \& 2): A linguo-labial cross-section picture was taken before the surface treatment of the labial central cusp were performed (Fig. $22 \mathrm{C} 1$ ). The cross-section reveals seemingly five different layers, same as in H. rapax (2). The SCE enamel range from approximately 70 to $80 \mu \mathrm{m}$ and is divided in two, one outer homogenous layer and an inner layer oriented perpendicular to the dentine surface, as in Acrodus and Polyacrodus (Fig. $22 \mathrm{C} 1$ \& 2). Remaining layers may be a result of a mixture of orthodentine and osteodentine, as for Lissodus angulatus in Blazejowski (2004).

Hybodus rapax (2) (PMO 230.336, Fig. 22 D1-3): The enameloid consist of a SLE layer, which range from 63 $\mu \mathrm{m}$ by the crown shoulder to $93 \mu \mathrm{m}$ at the occlusal crest. This cross-section is similar to the H. rapax (1) with the same division of the layers, except an additional not coherent thin pattern between the SLE layer and the dentine (Fig. 22 D2). The cross-section reveals seemingly five different layers, same as in H. rapax (2). The outer layer is divided in to two SLE layers, the first external layer is homogenous and the second internal layer has crystallites oriented perpendicular to the dentine surface, as in Acrodus and Polyacrodus (Fig. 22 D2 \& 3). The third to fifth layers may be a result of mixed osteodentin and dentin, or plausibly the $\mathrm{BCE}$ unit is present. 

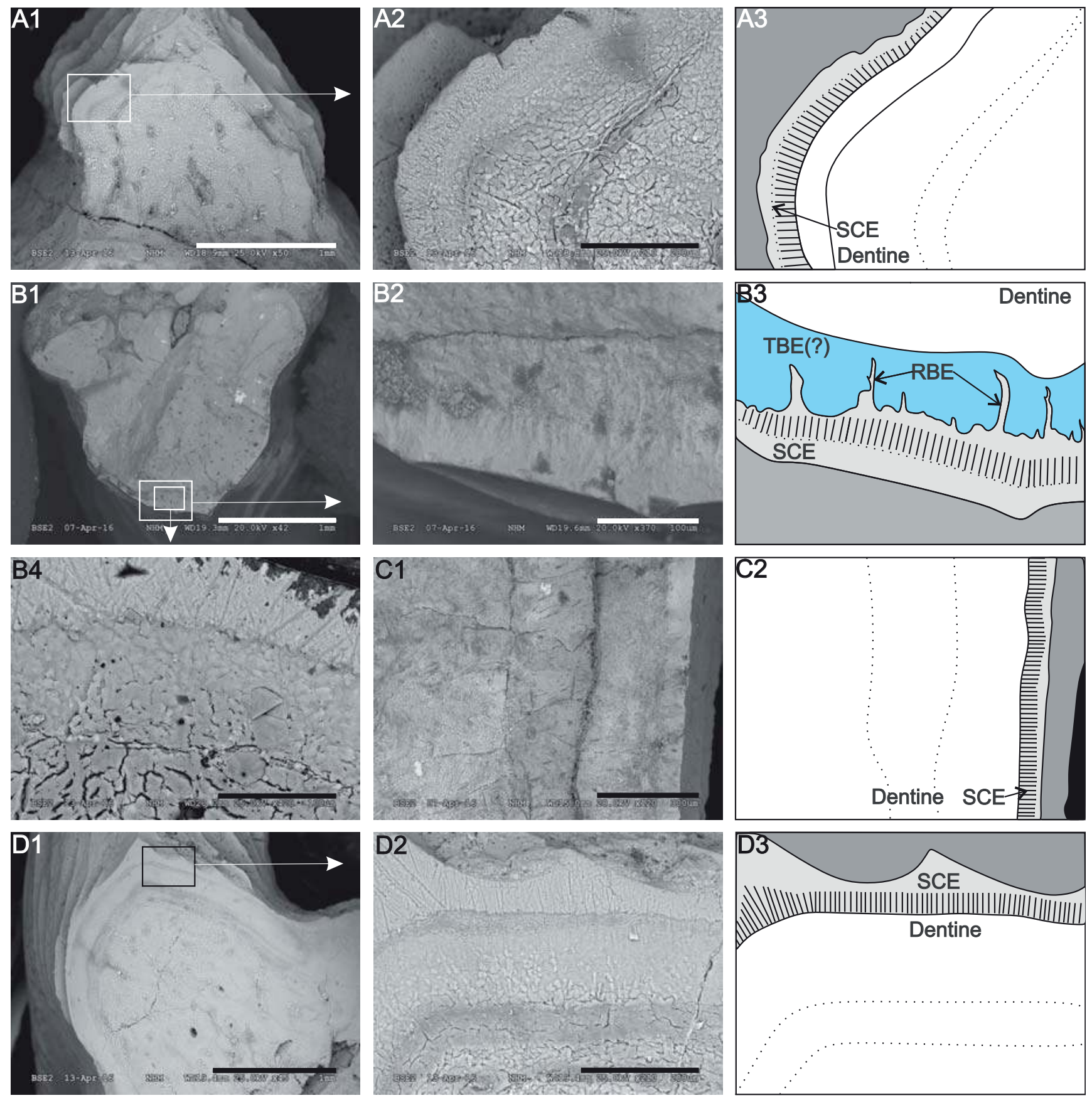

Figure 22. Tooth enameloid microstructure of: (A) Synechodontiformes sp. (2) PMO 230.126: A1 - Cross section of the tooth perpendicular to its mesiodistal axis. Scale bar $1 \mathrm{~mm}$. A2 - Section by the lingual crown shoulder (outline in A1). Scale bar $200 \mu \mathrm{m}$. A3 - Interpretation of A2. (B) Synechodontiformes sp. (1) PMO 230.335: B1-Cross section of the tooth perpendicular to its mesiodistal axis. Scale bar $1 \mathrm{~mm}$. B2 - Cross section by the labial side of occlusal crest (outline B1). Scale bar $100 \mu \mathrm{m}$. B3 - Interpretation of B2. B4-Magnified (and rotated) area of the labial side of the occlusal crest (outline B1). Scale bar $100 \mu \mathrm{m}$. (C) Hybodus rapax (1) PMO 230.143: C1 - Labial cross section perpendicular to its mesiodistal axis. Scale bar $300 \mu \mathrm{m}$. C2 - Interpretation of C1. (D) Hybodus rapax (2) (PMO 230.336): D1 - Cross section of the tooth perpendicular to its mesiodistal axis. Scale bar $1 \mathrm{~mm}$. D2 - Section of lingual side of occlusal crest (outline in D1). Scale bar $200 \mu \mathrm{m}$. D3 Interpretation of D2. See Table 2 for SEM preparations and parameters. RBE - radial bundled enameloid, SCE - single crystallite enameloid, TBE - tangled bundled enameloid.

\section{Discussion}

In this study, more than 550 chondrichthyan teeth, three fin spines and a cephalic spine were identified. The chondrichthyans identified in the material from the
Grippia bonebed collected in 2015 belongs to 7 genera and 15 species. A likely origin for the Grippia bonebed material is a coastal margin, the findings of a fragmented tooth plate of the lungfish Ceratodus and a fragmented Mytilis strengthens this idea. The pyrite present in the Grippia bonebed indicates anoxic to dysoxic water 
Table 2. SEM preparation parameters. $x$ - not performed.

\begin{tabular}{|c|c|c|c|c|c|c|c|c|c|}
\hline Fig. & Pic. & Species & $P M O$ & Treatment & Etched & Time & Gold alloy & Vacuum & Voltage $(k V)$ \\
\hline \multirow[t]{7}{*}{21} & $\mathrm{~A} 1$ & A. spitzbergensis & 230.334 & Polished & $10 \% \mathrm{HCl}$ & $120 \mathrm{~s}$ & 2 layers & High & 25 \\
\hline & A2 & A. spitzbergensis & 230.334 & Polished & $10 \% \mathrm{HCl}$ & $120 \mathrm{~s}$ & 2 layers & High & 25 \\
\hline & B1 & A. scaber & 230.109 & Polished & $10 \% \mathrm{HCl}$ & $120 \mathrm{~s}$ & 4 layers & High & 25 \\
\hline & B2 & A. scaber & 230.109 & Polished & $10 \% \mathrm{HCl}$ & $120 \mathrm{~s}$ & 4 layers & High & 25 \\
\hline & $\mathrm{C} 1$ & Polyacrodus sp. & 230.131 & Polished & $10 \% \mathrm{HCl}$ & $10 \mathrm{~s}$ & 2 layers & High & 25 \\
\hline & $\mathrm{C} 2$ & Polyacrodus sp. & 230.131 & Polished & $10 \% \mathrm{HCl}$ & $120 \mathrm{~s}$ & 4 layers & High & 25 \\
\hline & $\mathrm{C} 4$ & Polyacrodus sp. & 230.131 & Polished & $10 \% \mathrm{HCl}$ & $10 \mathrm{~s}$ & 2 layers & High & 25 \\
\hline \multirow[t]{8}{*}{24} & $\mathrm{~A} 1$ & Synechodontiformes sp. (2) & 230.126 & Polished & $10 \% \mathrm{HCl}$ & $120 \mathrm{~s}$ & 4 layers & High & 25 \\
\hline & A2 & Synechodontiformes sp. (2) & 230.126 & Polished & $10 \% \mathrm{HCl}$ & $120 \mathrm{~s}$ & 4 layers & High & 25 \\
\hline & B1 & Synechodontiformes sp. (2) & 230.335 & $\mathrm{x}$ & $\mathrm{x}$ & $\mathrm{x}$ & $\mathrm{x}$ & Low & 20 \\
\hline & B2 & Synechodontiformes sp. (2) & 230.335 & $\mathrm{x}$ & $\mathrm{x}$ & $\mathrm{x}$ & $\mathrm{x}$ & Low & 20 \\
\hline & B4 & Synechodontiformes sp. (2) & 230.335 & Polished & $10 \% \mathrm{HCl}$ & $120 \mathrm{~s}$ & 4 layers & High & 25 \\
\hline & $\mathrm{C} 1$ & H. rapax & 230.143 & $\mathrm{x}$ & $\mathrm{x}$ & $\mathrm{x}$ & $\mathrm{x}$ & Low & 20 \\
\hline & D1 & H. rapax & 230.336 & Polished & $10 \% \mathrm{HCl}$ & $120 \mathrm{~s}$ & 4 layers & High & 25 \\
\hline & D2 & H. rapax & 230.336 & Polished & $10 \% \mathrm{HCl}$ & $120 \mathrm{~s}$ & 4 layers & High & 25 \\
\hline
\end{tabular}

conditions (Bond \& Wignall, 2010), which could have been developed in a coastal dysoxic area, or, most likely, at the cold deep-water shelf.

H. sasseniensis is previously only known from the Myalina bed(s) (Brevassfjellet) from the older Dienarian substage (Stensiö, 1921), and after this study also from the Spathian substage. The $H$. sasseniensis teeth described in this study have up to 7 lateral cusplets next to the central cusp (e.g., PMO 230.107), which previously has not been observed in this species from Spitsbergen (e.g., Stensiö, 1921; Birkenmajer \& Jerzmanska, 1979; Blazejowski, 2004). According to Stensiö (1921) and Birkenmajer \& Jerzmanska (1979), the number of lateral cusplets on the crown depends on the mesiodistal length of the tooth, which also applies for the material in this study. Another observation for $H$. sasseniensis is that along with the increase of lateral cusplets and mesiodistal length, the linguo-labial grooves becomes more apical-concave. The increase of apical-concavity is perhaps due to a lateral to posterior position in the jaw or as an occasion of mesiodistal elongation. The identified $H$. sasseniensis material is divided in two groups, based on the size differences. Although the "regular" group has specimens with same mesiodistal length or linguo-labial width, the majority is noteworthy smaller, especially in the latter direction. The 14 teeth described by Birkenmajer \& Jerzmanska (1979) range from a mesiodistal length of 1 to $7 \mathrm{~mm}$, which are generally smaller than the "regular" group of
H. sasseniensis described in this study. Stensiö (1921) described 6 teeth with mesiodistal length ranging from 6 to $12 \mathrm{~mm}$, which are the same size as the range in the "regular" group, while they are mesiodistally shorter than the massive group of $H$. sasseniensis. The size distribution in a species is considered to have a gradual distribution, e.g., from anterior to posterior position in a jaw, between upper or lower jaw or from young to adult specimens (Cappetta, 2012). Therefore the size difference between the "regular" and the massive group in this study is highly interesting. One possible conclusion may be that the massive group could belong to another species than $H$. sasseniensis. However, the major difference is the size while the morphology is the same as the "regular" group. Another interpretation may be that the species rarely grows to large sizes, but when they first manage, they grow to noteworthy sizes. A third explonation is that both the "regular" and massive group of teeth may be found in the same jaw of a $H$. sasseniensis. To verify any of these interpretations articulated material would have to be obtained.

The presence of Hybodus microdus in this material is questionable. Stensiö (1921) established the species with two main characteristic features; being small and with slight ornamentation. The teeth described herein have ornamentation on the crown and a massive cusp base, similar to Stensiö (1921), but they are not small. The maximal mesiodistal lengths of Stensiö (1921)'s teeth are approximately $1.5 \mathrm{~mm}$, while the teeth in this 
material range to a mesiodistal length of $11.3 \mathrm{~mm}$. The large difference could be a product of the surface picking conducted by Stensiö (1921), where he collected a small matrix block with imbedded fossils, compared to the larger amount of material collected for this study. The large amount of material may have provided a greater range of teeth; however, smaller teeth could have been preserved in the $1 \mathrm{~mm}$ fraction from the sieving of the material that has not yet been studied. The H. microdus specimens described in Birkenmajer \& Jerzmanska (1979) has a mesiodistal length up to $3.5 \mathrm{~mm}$. One feature that slightly contradicts the identification of the Hybodus genus is the apico-basal tall root, which resembles more an Acrodus. This morphological feature may indicate a different species or in fact different genus and could be a result of heterodont dentition.

The majority of species in the Hybodus genus is repeatedly thought to be synonyms or morphospecies (Stensiö, 1921; Brinkmann \& Jerzmanska, 1979; Rieppel, 1981). Stensiö (1921) regarded the Agassiz splitting of the genus Hybodus into several species as unnecessary, since most of the species should be considered as morphospecies. However, due to the small amount of specimens the differences were still significant (Stensiö, 1921). At the same time, Stensiö (1921) established that the species $H$. rapax undeniably resembled the H. longiconus, which Agassiz defined in 1843. Rieppel (1981) described that the H. longiconus resembles the teeth of H. plicatilis, while the H. sasseniensis in this study resembles the teeth of the latter species. The $H$. plicatilis is characterized by the straight and pointed central cusp, vertical striations apical radiating towards the apex and the root with approximately vertical linguo-labial grooves (Rieppel, 1981). This description for H. plicatilis fits well with the description of $H$. sasseniensis herein. In 1921, Stensiö established both H. rapax and H. sasseniensis, but with a precaution that with better material the studies may provide a similarity in which case they should be put in the same species. The same point of issue is being taken into account in this study and it is likely that $H$. rapax and $H$. sasseniensis belong to the same species. As a result, the difference of $H$. rapax and $H$. sasseniensis teeth is unclear and the two species should be considered as one species for which H. sasseniensis Stensiö 1918 has nomenclatural priority.

The Polyacrodus sp. (PMO 230.130-131) has not been assigned to a species because of few teeth and difficulties identifying the species. Polyacrodus pyramidalis (Stensiö, 1921, plate 1, fig. 21-26) has the same lingual peg with approximately the same ratio of linguo-labial thickness and mesiodistal length as the Polyacrodus sp. in this new material, but the crown has no lateral cusplets. The teeth described by Stensiö (1921) are significantly smaller (linguo-labial length of $1.5-2.0 \mathrm{~mm}$ and apico-basal height of $0.5-0.75 \mathrm{~mm}$ ) compared to teeth described in this study and they are from a younger unit at Mt. Bertil (Upper Triassic), while the Polyacrodus polycyphus
Agassiz, 1837 is described by Diedrich (2009) to have similar size and lateral cusplets. The Polyacrodus genus differs from the Hybodus genus by having the lateral cusplets oriented closer together and with no high or extremely dominant central cusp. Comparing the Polyacrodus to Acrodus genus shows that they have similar apico-basal high root while the Acrodus has no central cusp or lateral cusplets such as the Polyacrodus genus. Based on these observations and the enamel study (which will be discussed later), the specimens are assigned to the Polyacrodus genus and referred to as Polyacrodus sp.

Acrodus scaber was established by Stensiö (1921) based on small fragments and two fairly preserved crowns collected from the Lower Triassic bonebed at Mt. Congress, Spitsbergen, by Prof. Dr. W. Salomon in 1910. The striations are coarser than those of A. spitzbergensis, which can also be observed in this material, nevertheless Stensiö (1921) stated that the species resembled each other greatly. These two species are also found in this study and support Stensiös (1921) observation. However, there may still be morphological differences dividing the species. A. scaber is mesiodistally longer, apico-basally higher and linguo-labially broader than the remaining Acrodus species in this study. However, the tooth size is not enough to fully distinguish the species. The size may vary due to a monognathic or diagnathic heterodonty, sexual dimorphism or even differences between young and adult specimens (Cappetta, 2012).

The Acrodus oppenheimeri specimens collected by Stensiö (1921) was not given a specific location, but are linked to the areas: "Mt. Tschermak, Mt. Saurie and south of Sassen Bay on the mountain between De Geer Valley and Flower Valley" (Stensiö, 1921, p.25). The Acrodus oppenheimeri in this study differs from the teeth collected by Stensiö (1921, plate 3, fig. 5-11, P.105 and pers.obs. J.B.) by being mesiodistally straighter, smaller and without any lateral cusplets. This is perhaps due to its different position in the jaw rather than to different species, hence the reconstruction of the jaw done by Stensiö (1921), where the posterior teeth are significantly different to the anterior. Birkenmajer \& Jermanzka (1979) have described a tooth with the same morphology, but they assign it to A. spitzbergensis rather than an A. oppenheimeri. This does not correspond with the results in this study, proving how difficult it is to determine species according to the striations and shape.

This study is the first to describe Acrodus gaillardoti from Spitsbergen. Diedrich (2009) previously observed the species in the Middle Triassic (Anisian-Ladinian boundary) from the Upper Muschelkalk bonebed, Bissendorf, Germany. Earlier findings of the species also refer to the mainland Europe Muschelkalk unit, e.g France (Woodward, 1889). The species resembles the A. oppenheimeri, but without the distinct occlusal crest and with a linguo-labial crown bulging, which are the characteristic features that separate the species. Delsate 
\& Duffin (1999) stated that A. gaillardoti is significantly larger than A. lateralis, while in this study the mesiodistal length and linguo-labial width between those species are similar. The A. gaillardoti may be a morphospecies of A. spitzbergensis and A. scaber; however, to strengthen this hypothesis, articulated specimens would have to be obtained.

The Acrodus sp. differs from the Acrodus lateralis by a mesiodistal flatter crown without any striations or crests (smooth and shiny surface). In general the A. lateralis has striations extending throughout the crown (Diedrich, 2009; Henz \& Hertel, 2012; Böttcher, 2015) and occlusal crest (e.g., Delsate \& Duffin, 1999). The crown in Acrodus sp. is more linguo-labial slender than the crown in A. lateralis. However, the Acrodus sp. is not excluded from belonging to $A$. lateralis in this study.

The presence of only one tooth of Lissodus angulatus does not necessarily indicate that the species is infrequent in the Grippia bonebed; it may have been sieved through the $2 \mathrm{~mm}$ fraction and is preserved in the $1 \mathrm{~mm}$ fraction material not yet studied.

The hybodontoidea fin and cephalic spines are rarely possible to sign to a specific hybodont genera or species due to only small differences. Unless the spines are found with one type of teeth, the attribution to different genera or species is almost impossible (Cappetta, 2012). The material from this study is not articulated, which enhances the difficulties in determining the genera or species of the spines. Therefore, the two fin spines and one cephalic spine have been attributed to the superfamily Hybodontoidea.

The neoselachian are viewed as the sister group to the hybodonts (Maisey, 1982, 1984; Klug, 2010). Due to the hybodonts originating in the Carboniferous, the early origin of the neoselachian is highly possible (Klug, 2010; Andreev \& Cuny, 2012). The only previously evidence of neoselachian from Spitsbergen was the discovery of a Nemacanthus fin spine by Stensiö (1921). Parts of similar fin spines are also identified from the material used in this study. The neoselachian teeth are a new discovery from Spitsbergen and this material consists of two new species ( 1 and 2 ) assigned to the neoselachian: Synechodontiformes sp. 1 and 2 (Fig. 18 \& 19). The proper description of the new species is awaiting more material from the bonebed in the process of being washed.

The Synechodontiformes sp. (1) has cutting edge radiating to the apex of the central cusp and through the cusplets. The teeth resemble the Mucrovenator minimus Cuny et al. (2001) (Anisian, Nevada) by the cutting edge, conical shape of central cusp and apico-basal narrow root. The major difference is, amongst others, the size.

The M. minimus teeth described by Cuny et al. (2001) range from a mesiodistal length and apico- basal height never exceeding $2.5 \mathrm{~mm}$, while the teeth described from Grippia bonebed range up to a mesiodistal length of 11.3 and an apico-basal height of $7.3 \mathrm{~mm}$. The teeth described here are slightly older, (late Olenekian, Spathian) than the $M$. minimus from the Anisian of Nevada (Cuny et al., 2001).

Synechodontiformes sp. (2) PMO 230.117 has similar mesiodistal elongated cutting edge, low central cusp and the crown firmly attached to the root as the species Duffinselache holwellensis (Synechodontiformes) from Rhaetian (late Triassic), England (Andreev \& Cuny, 2012). However, the Duffinselache holwellensis (Duffin, 1998) differs from PMO 230.117 by not having any vertical striations or lateral sub-cusplets. The Duffinselache holwellensis was previously interpreted as a hybodont genus by Duffin (1998) named "Polyacrodus" holwellensis. Andreev \& Cuny (2012) signed the species to genus Duffinselache and stated that the root was rarely preserved among hybodonts. This statement is contradictory to the material from the Grippia bonebed. Almost all of the hybodont teeth have the root preserved.

The presence of $\mathrm{RBE}$ and $\mathrm{PBE}$ in the enameloid of shark teeth reinforces the present of neoselachian in this study. The BCE unit is not recognized in the enameloid of Acrodus, Hybodus or Polyacrodus in the untreated or acid treated cross-sections. While the $\mathrm{RBE}$ are clearly recognized in Synechodontiformes sp. (1) in the untreated section, the PBE and TBE is more unnoticeable, but this may be due to the fact that in general the TBE layer is poorly developed in primitive Neoselachian (Cuny \& Risnes, 2005). Synechodontiformes sp. (2) has clear indications of $\mathrm{RBE}$ in the untreated surface and possible a $\mathrm{PBE}$ and TBE, as in Synechodontiformes sp. (2), although Cuny \& Risnes (2005) states that RBE is poorer developed in the Triassic Synechodontiformes than the more modern neoselachians. The presence of $\mathrm{RBE}$ and $\mathrm{PBE}$ supports together with the morphological studies the occurrence of Synechodontiformes at Spitsbergen. The weak presence of the delicate BCE units might be due to the preparation of the specimens, which requires being accurate and careful. As stated by Cuny et al. (2001, p 296) - "No tangled-bundled enameloid (TBE) has been found, but this might be due to the difficulty of correctly preparing such minute teeth"

The presence of neoselachian in our sample changes the perspective of the shallow epicontinental ecosystem in the Spathian substage. The three different trophic adaptions; grinding- tearing- and cuttingtype found in the assemblage, are indications of the different ways the shark obtained their food. Both sharks with tearing- and cutting-type dentition indicate more active hunters than the sharks with grinding-type dentition. This implies a competitive environment. 
The neoselachian teeth are used for scratching and butchering, while the teeth of some hybodonts (e.g., Hybodus) are used for capturing and holding on to their prey. The first great radiation of the neoselachians is usually identified to the Rhaetian, as a result of rapid transgression creating epicontinental seas (Cuny \& Benton, 1999; Klug, 2010). The appearance of two different synechodontiforms in the Grippia bonebed could be a hint of an earlier radiation of the neoselachians.

Hybodont teeth from the Early Triassic (Schytian (old terminology)) Induan-Olenekian are found on the Japanese islands, such as Polyacrodus minimus (Agassiz, 1839) and an unidentified Hybodontidae indet. (Goto, 1994). In China, in the Middle to Late Triassic, several hybodont teeth have been identified, such as Polyacrodus contrarius (Chen et al., 2007). These findings have a similar lingual peg as Polyacrodus sp. in this study; however the teeth show several distinct differences such that they can only be related to the same genus. Neoselachian teeth are identified from the LadinianCarnian (Chen et al., 2007), but they do not resemble the neoselachian teeth from Spitsbergen with their apical high and sharp lateral cusplets next to a massive central cusp.

The Early Triassic from Oman consists of Hybodontiformes and neoselachian shark teeth, which rarely extends more than $2 \mathrm{~mm}$ mesiodistally (Koot, 2013). These teeth are significantly smaller than the observed teeth in the Grippia bonebed, but are similar to the older teeth described by Stensiö (1921) and Birkenmajer \& Jerzmanska (1979). The observations may indicate an increase of the chondrichthyan body size during the Early Triassic. The invertebrates were restricted in body size during the earliest of Induan (Twitchett, 2006), which may have influenced the chondrichthyan body size. The Neotethys (Oman, India, Timor and Iran) are, according to Koot (2013), similar in composition of hybodonts and neoselachian sharks.

\section{Conclusions}

- This study provides a well preserved chondrichthyan substage from the Early Triassic of Spitsbergen. The Grippia bonebed is the richest discovery of Early Triassic chondrichthyan teeth from Spitsbergen. Of the 15 identified species, wherein eight are new for the Grippia niveau, contributes greatly to the understanding of chondrichthyans after the PTME. The teeth are well preserved and often with the root firmly attached to the crown, which is a rare preservation for hybodont teeth that are usually missing the root.
- The Hybodus sasseniensis have up to 7 lateral cusplets next to the central cusp, which previously has not been found in this species from Spitsbergen. This species is only known from the older Dienarian substage, but now also from the younger Spathian substage. The H. sasseniensis is represented by two groups, "regular" and massive, depending on the size. The massive group consists of the largest identified $H$. sasseniensis from Spitsbergen.

- In the determination of shark species, the heterodont dentition is frequently overlooked and the occurrence of morphospecies is therefore common. This study raises a question about the close resemblance of Hybodus sasseniensis and $H$. rapax, Acrodus scaber and A. spitzbergensis and between Acrodus species in general.This is also true for the variations in teeth size of a monognathic or diagnathic heterodont dentition, sexual dimorphism and even between young and adults.

- The presence of Hybodus microdus Stensiö (1921) in the Grippia bonebed is questionable due to the more than 7 times larger mesiodistal length and an apicobasal higher root than the teeth previously described by Stensiö (1921). However, the close resemblance of the morphology of the teeth indicates that they belong to the same species, and that the "lilliput effect" may have influenced the marine life after the PTME.

- This study is the first to describe Acrodus gaillardoti from Spitsbergen, whereas it is previously known from the younger Anisian-Ladinian Upper Muschelkalk bonebed. The species differs from the Acrodus oppenheimeri by the central linguo-labial bulging of the crown and lack the mesiodistally elongated occlusal crest. However, the A. gaillardoti is not excluded from being morphospecies of $A$. scaber and A. spitzbergensis.

- The neoselachian teeth are a new discovery from Spitsbergen and the material in this study consists of two new species of the Synechodontiformes. With their cutting edges and multiple enameloid layers they differ considerably from the identified Hybodontiformes in the Grippia bonebed.

- The shallow epicontinental to deep water shelf-areas in the Spathian Boreal sea contained a majority of active chondrichthyan hunters with cutting and tearing dentition, and a smaller amount of durophagous chondrichthyans with grinding dentition. The chondrichthyans indicate an endemic and latitudinal restriction in the Smithian - Spathian, also supported by the ammonoids known from the Vikinghøgda Formation.

- To better understand the chondrichthyans survival and diversity after the PTME, the discovery of articulated 
material is needed. This would give the possibility to differentiate the morphospecies from the true species.

Acknowledgements. A special thanks to all volunteers that helped with the excavation of the material in the short arctic summer of 2015. Thanks to PMU and Benjamin Kear for inviting us to study their collection. Thanks to Spitsbergen travel, National Geographic, Bayerngas Norge, Tullow Oil and CGG for financing field work. David L. Bruton did a very helpful last edit of the manuscript. Thanks to the reviewer Chris Duffin and anonymous reviewer for a lot of constructive suggestions.

\section{References}

Agassiz, L.1837: Recherches Sur Les Poissons Fossiles. Tome III (livr. 8, 9). Imprimérie de Petitpierre, Neuchatel, 72 pp.

Agassiz, L.1839: Recherches Sur Les Poissons Fossiles. Tome III (livr. 10, 12). Imprimérie de Petitpierre, Neuchatel, 390 pp.

Allard, H., Carpenter, S.C., Duffin, C.J. \& Benton, M.J. 2015: Microvertebrates from the classic Rhaetian bone beds of Manor Farm Quarry, near Aust (Bristol, UK). Proceedings of the Geologists' Association 126 (6), 762-776.

Andreev, P. \& Cuny, G. 2012: New Triassic stem selachimorphs (Chondrichthyes, Elasmobranchii) and their bearing on the evolution of dental enameloid in Neoselachii. Journal of Vertebrate Paleontology, 32, 255-266. https://doi.org/10.1080/02724634.2012.644646.

Benton, M.J. 1998: The quality of the fossil record of vertebrates. In Donovan, S.K. \& Paul, C.R.C. (eds.): The adequacy of the fossil record, Wiley, New York, pp. 269-303.

Benton, M.J. 2015: Vertebrate palaeontology, fourth edition. WileyBlackwell, Chichester, 480 pp.

Benton, M.J., Zhang, Q., Hu, S., Chen, Z.Q., Wen, W., Liu, J., Huang, J., Zhou, C., Xie, T., Tong, J. \& Choo, B. 2014: Exceptional vertebrate biotas from the Triassic of China, and the expansion of marine ecosystems after the Permo-Triassic mass extinction. Earth-Science Reviews 137, 85-128.

https://doi.org/10.1016/j.earscirev.2014.08.004.

Berra, T.M. 2001. Freshwater Fish Distribution. Academic Press, San Diego. 607 pp.

Birkenmajer, K. \& Jerzmanska, A. 1979: Lower Triassic shark and other fish teeth from Hornsund, South Spitsbergen. Studia Geologica Polonica, 60, 7-37.

Blazejowski, B. 2004: Shark teeth from the Lower Triassic of Spitsbergen and their histology. Polish Polar Research 25, 153-167.

Bond, D.P.G. \& Wignall, P.B. 2010: Pyrite framboid study of marine Permian-Triassic boundary sections: a complex anoxic event and its relationship to contemporaneous mass extinction. Geological Society of American Bulletin 122, 1265-1279.

https://doi.org/10.1130/B30042.1.

Böttcher, R. 2015: Fische des Lettenkeupers. Palaeodiversity 8, 141-202.

Cappetta, H. 1987: Chondrichthyes II Mesozoic and Cenozoic Elasmobranchii, Handbook of Paleoichthyology, 3B. Gustav Fischer Verlag, Stuttgart, 193 pp.

Cappetta, H. 2012: Chondrichthyes. Mesozoic and Cenozoic Elasmobranchii: Teeth. Handbook of Paleoichthyology, 3E. Gustav Fischer Verlag, Stuttgart, 512 pp.

Chen, L., Cuny, G. \& Wang, X. 2007: The chondrichthyan fauna from the Middle-Late Triassic of Guanling (Guizhou province, SW China). Historical Biology 19, 291-300.

https://doi.org/10.1080/08912960701248234.
Chrzastek A. 2008: Vertebrate remains from the Lower Muschelkalk of Raciborowice Górne (North-Sudetic Basin, SW Poland). Geological Quarterly 52, 225-237.

Cione, A.L., Acosta Hospitaleche, C., Mennucci, J.A. \& Cocca, S. 2002: The first shark from the Triassic-Jurassic of South America. Neues Jahrbuch für Geologie und Paläontologie Monatshefte 1, 9-18.

Cox, C.B. \& Smith, D.G. 1973: A review of the Triassic vertebrate faunas of Svalbard. Geological Magazine 110, 405-418. https://doi.org/10.1017/S0016756800036190.

Cuny, G. \& Benton, M.J. 1999: Early radiation of the neoselachian sharks in Western Europe. Geobios 32, 193-204. https://doi.org/10.1016/S0016-6995(99)80032-1.

Cuny, G. \& Risnes, S. 2005. The enameloid microstructure of the teeth of Synechodontiform sharks (Chondrichthyes: Neoselachii). Vertebrate Palaeontology 3, 8-19.

Cuny, G., Rieppel, O. \& Sander, P.M. 2001: The shark fauna from the Middle Triassic (Anisian) of North-Western Nevada. Zoological Journal of the Linnean Society 133, 285-301. https://doi.org/10.1111/j.1096-3642.2001.tb00627.x.

Delsate, D. \& Duffin, C.J. 1999: A new fish fauna from the Middle Triassic (Upper Muschelkalk) of Moersdorf (Grand Duchy of Luxembourg). Travaux scientifiques du Musée national d'histoire naturelle, Luxembourg 32, 5-53.

Diedrich, C. 2009: The vertebrates of the Anisian/Ladinian boundary (Middle Triassic) from Bissendorf (NW Germany) and their contribution to the anatomy, palaeoecology, and palaeobiogeography of the Germanic Basin reptiles. Palaeogeography, Palaeoclimatology, Palaeoecology 273, 1-16. https://doi.org/10.1016/j.palaeo.2008.10.026.

Duffin, C.J. 1985: Revision of the hybodont selachian genus Lissodus Brough (1935). Palaeontographica Abteilung A 188, 105-152.

Duffin. C.J. 1998. New shark remains from the British Rhaetian (latest Triassic) 2. Hybodonts and palaeospinacids. Neues Jahrbuch für Geologie und Paläontologie 4, 240-256.

Duffin, C.J. \& Ward, D.J. 1993: The Early Jurassic palaeospinacid sharks of Lyme Regis, southern England. Belgian Geological Survey, Professional Paper: Elasmobranches et Stratigraphie 264, 53-101.

Ekeheien, C.P., Delsett, L.L., Roberts, A.J. \& Hurum, J.H. 2018: Preliminary report on ichthyopterygian elements from the Early Triassic (Spathian) of Spitsbergen. Norwegian Journal of Geology 98, 219-237. https://dx.doi.org/10.17850/njg98-2-07.

Enault, S., Guinot, G., Koot, M.B. \& Cuny, G. 2015: Chondricthyan tooth enameloid: past, present and future. Zoological Journal of the Linnean Society 174, 549-570. https://doi.org/10.1111/zoj.12244.

Erwin, D.H. 1998: The end and the beginning: recoveries from mass extinctions. Trends in Ecology \& Evolution 13, 344-349. https://doi.org/10.1016/S0169-5347(98)01436-0.

Evans, H.M. 1904: A new cestraciont spine from the lower Triassic of Idaho. University of California Publications - Bulletin of the Department of Geology 3, 397-402.

Frebold, H. 1930: Die Altersstellung des Fischhorizontes, des Grippianiveaus und des unteren Saurierhorizontes in Spitzbergen. Skrifter om Svalbard og Ishavet 28, 1-36.

Goto, M. 1994: Palaeozoic and early Mesozoic fish faunas of the Japanese Islands. The Island Arc 3, 247-254. https://doi.org/10.1111/j.1440-1738.1994.tb00114.x.

Guinot, G., Adnet, S. \& Cappetta, H. 2012: An Analytical Approach for Estimating Fossil Record and Diversification Events in Sharks, Skates and Rays. PLoS ONE 7, 1-10. https://doi.org/10.1371/journal.pone.0044632.

Hallam, A. \& Wignall, P.B. 1997: Mass Extinctions and Their Aftermath. Oxford University Press, New York, 320 pp.

Hansen, B.B., Hammer, Ø. \& Nakrem, H.A. 2018: Stratigraphy and age of the Grippia niveau bonebed, Lower Triassic Vikinghøgda Formation, Spitsbergen. Norwegian Journal of Geology 98, 175-187. https://dx.doi.org/10.17850/njg98-2-02. 
Henz, M. \& Hertel, S. 2012: Trias Fossilien - 2. Teil. - Selachier der Trias Mainfrankens Folge A. Steinkern.de, pp. 5.

Hounslow, M.W., Peters, C., Mørk, A., Weitschat, W. \& Vigran, J.O. 2008: Biomagnetostratigraphy of the Vikinghøgda Formation, Svalbard (Arctic Norway), and the geomagnetic polarity timescale for the Lower Triassic. Geological Society of America, Bulletin 120, 1305-1325. https://doi.org/10.1130/B26103.1.

Hulke, J.W. 1873: Memorandum on some fossil vertebrate remains collected by the Swedish expeditions to Spitzbergen in 1864 and 1868. Bihang till Kungliga Svenska Vetenskapsakademiens Handlingar 1, Afdeling IV, 9, 1-11.

Hurum, J.H., Engelschiøn, V.S., Økland, I., Bratvold, J., Ekeheien, C., Roberts, A.J., Delsett, L.L., Hansen, B.B., Mørk, A., Nakrem, H.A., Druckenmiller, P.S. \& Hammer, Ø. 2018: The history of exploration and stratigraphy of the early to middle Triassic vertebrate bearing strata of Svalbard (Sassendalen Group, Spitsbergen). Norwegian Journal of Geology 98, 165-174.

https://dx.doi.org/10.17850/njg98-2-04.

Jaekel, O. 1889: Die Selachier aus dem oberen Muschelkalk Lothringens. Abhandlungen der Geologischen Specialkarte ElsassLothringen 3, 273-332.

Klug, S. 2008: Morphology and phylogeny of Synechodontiform sharks (Chondrichthyes, Elasmobranchii) with comments on the origin and early evolution of Neoselachii. PhD thesis, Freie Universität Berlin, $31 \mathrm{pp}$.

Klug, S. 2010: Monophyly, phylogeny and systematic position of the $\dagger$ Synechodontiformes (Chondrichthyes, Neoselachii). Zoologica Scripta 39, 37-49.

https://doi.org/10.1111/j.1463-6409.2009.00399.x.

Kriwet, J., Kiessling, W. \& Klug, S. 2009: Diversification trajectories and evolutionary life-history traits in early sharks and batoids. Proceedings of the Royal Society B-Biological Sciences 276, 945-951. https://doi.org/10.1098/rspb.2008.1441.

Korneisel, D., Gallois, R.W., Duffin, C.J. \& Benton, M.J. 2015: Latest Triassic marine sharks and bony fishes from a bone bed preserved in a burrow system, from Devon, UK. Proceedings of the Geologists' Association 126, 130-142.

Koot, M.B. 2013: Effects of the Late Permian mass extinction on chondrichthyan palaeobiodiversity and distribution patterns. $\mathrm{PhD}$ thesis, Plymouth University, $853 \mathrm{pp}$.

Long, J.A. 1995: The Rise of Fishes: 500 Million Years of Evolution. Johns Hopkins University Press, Baltimore and London, $223 \mathrm{pp}$.

Maisey, J.G. 1982: The Anatomy and Interrelationships of Mesozoic Hybodont Sharks. American Museum Novitates 2724, 1-48.

Maisey, J.G. 1984: Chondrichthyan phylogeny: a look at the evidence. Journal of Vertebrate Paleontology 4, 359-371. https://doi.org/10.1080/02724634.1984.10012015.

Maxwell, E.E. \& Kear, B.P. 2013: Triassic ichtyopterygian assemblages of the Svalbard archipelago: a reassessment of taxonomy and distribution. Journal of the Geological Society of Sweden 135, 85-94.

Mørk, A., Elvebakk, G., Forsberg, A.W., Hounslow, M.W., Nakrem, H.A., Vigran, J.O. \& Weitchat, W. 1999: The type section of the Vikinghøgda Formation: a new Lower Triassic unit in central and eastern Svalbard. Polar research 18, 51-82. https://doi.org/10.3402/polar.v18i1.6558.

Nielsen, E. 1952: On new or little known Edestidae from the Permian and Triassic of East Greenland. Meddelelser om Grønland 144, 1-55.

Nordenskiöld, A.E. 1867: Sketch of the geology of Spitzbergen. P.A. Norstedt \& Söner, Stochholm, 55 pp.

Patterson, C. \& Smith, A.B. 1987: Is the periodicity of extinctions a taxonomic artefact? Nature 330, 248-252.

https://doi.org/10.1038/330248a0.

Rieppel, O. 1981: The hybodontiform sharks from the Middle Triassic of Mte. San Giorgio, Switzerland. Neues Jahrbuch für Geologie und Paläontologie, Abhandlungen 161,324-353.
Romano, C. \& Brinkmann, W. 2010: A new specimen of the hybodont shark Palaeobates polaris with three-dimensionally preserved Meckel's cartilage from the Smithian (Early Triassic) of Spitsbergen. Journal of Vertebrate Paleontology 30, 1673-1683.

https://doi.org/10.1080/02724634.2010.521962.

Romano, C., Koot, M.B., Kogan, I., Brayard, A., Minikh, A.V. Brinkmann, W., Bucher, H. \& Kriwet, J. 2016: Permian - Triassic Osteichthyes (bony fishes): diversity dynamics and body size evolution. Biological Reviews 91, 106-147. https://doi.org/10.1111/brv.12161.

Schaeffer, B. 1973: Fishes and the Permian-Triassic boundary. In Logan, A. \& Hills, L.V. (eds.): The Permian and Triassic systems and their mutual boundary, Memoir of the Canadian Society of Petroleum Geologist 2, pp. 493-497.

Scheyer, T.M., Romano, C., Jenks, J. \& Bucher, H. 2014: Early Triassic Marine Biotic Recovery: The Predators' Perspective. PLoS ONE 9, 1-20. https://doi.org/10.1371/journal.pone.0088987.

Schultze, H.P. 2004. Mesozoic sarcopterygians. In Arratia, G. \& Tintori, A. (eds.): Mesozoic Fishes III, Verlag Dr. Friedrich Pfeil, Munich, pp. 463-492.

Stensiö, E.A. 1918: Notes on some fish remains collected at Hornsund by the Norwegian Spitzbergen Expedition in 1917. Norsk Geologisk Tidsskrift 5, 75-78.

Stensiö, E.A. 1921: Triassic fishes from Spitsbergen, Part I. Adolf Holzhausen, Vienna, 307 pp.

Stensiö, E.A. 1932: Triassic Fishes from East Greenland. Meddelelser om Grønland 83, 1-305.

Storrs, G.W. 1994: Fossil vertebrate faunas of the British Rhaetian (latest Triassic). Zoological Journal of the Linnean Society 112, 217259. https://doi.org/10.1111/j.1096-3642.1994.tb00319.x.

Straube, N., Schliewen, U. \& Kriwet, J. 2008: Dental structure of the Giant lantern shark Etmopterus baxteri (Chondrichthyes: Squaliformes) and its taxonomic implications. Environmental Biology of Fishes 82, 133-141. https://doi.org/10.1007/s10641-007-9264-z.

Thomson, K.S. 1977: The Pattern of Diversification among Fishes. In Hallam, A. (ed.): Patterns of evolution as Illustrated by the Fossil Record, Developments in Palaeontology and Stratigraphy 5, pp. 377-404. https://doi.org/10.1016/S0920-5446(08)70332-7.

Twitchett, R.J. 2006: The palaeoclimatology, palaeoecology and palaeoenvironmental analysis of mass extinction events. Palaeogeography, Palaeoclimatology, Palaeoecology 232, 190-213. https://doi.org/10.1016/j.palaeo.2005.05.019.

Vigran, J.O., Mangerud, G., Mørk, A., Worsley, D., Hochuli, P.A. 2014: Palynology and geology of the Triassic succession of Svalbard and the Barents Sea. Geological Survey of Norway Special Publication 14, $1-270$.

Wignall, P.B., Morante, R. \& Newton, R., 1998: The Permo-Triassic transition in Spitsbergen: $\delta^{13} \mathrm{C}_{\text {org }}$ chemostratigraphy, Fe and $\mathrm{S}$ geochemistry, facies, fauna and trace fossils. Geological Magazine 135, 47-62. https://doi.org/10.1017/S0016756897008121.

Wiman, C. 1910: Ichthyosaurier aus der Trias Spitzbergens. Bulletin of the Geological Institute of the University of Uppsala 9, 124-148.

Wiman, C. 1928: Eine neue marine Reptilien-Ordnung aus der Trias Spitzbergens. Bulletin of the Geological Institute of the University of Uppsala 22, 183-196.

Woodward, A.S. 1889: Catalogue of the fossil fishes in the British Museum, 1. British Museum (Natural History), London, xlvii +474 pp. 